Fructosylation of hydroxytyrosol by the $\beta$-fructofuranosidase from Xanthophyllomyces dendrorhous: Insights into the molecular basis of the enzyme specificity

N. Míguez, M. Ramírez-Escudero, M. Gimeno-Pérez, A. Poveda, J. Jiménez-Barbero, A. O. Ballesteros, M. Fernández-Lobato, J. Sanz-Aparicio,* and F. J. Plou*

Published in:

ChemCatChem 2018, 10, 4878 -4887

(DOI: https://doi.org/10.1002/cctc.201801171) 


\section{Fructosylation of hydroxytyrosol by the $\beta$-fructofuranosidase from Xanthophyllomyces dendrorhous: Insights into the molecular basis of the enzyme specificity}

N. Míguez,[a] M. Ramírez-Escudero,[b] M. Gimeno-Pérez,[c] A. Poveda,[d] J. Jiménez-Barbero,[d] A. 0. Ballesteros, ${ }^{[a]}$ M. Fernández-Lobato, ${ }^{[c]}$ J. Sanz-Aparicio, ${ }^{*[b]}$ and F. J. Plou*[a]

[a] N. Míguez, Prof. Dr. A. O. Ballesteros, Dr. F. J. Plou* Biocatalysis Department Institute of Catalysis and Petrochemistry (CSIC) Marie Curie 2, 28049 Madrid, Spain E-mail: fplou@icp.csic.es

[b] Dr. M. Ramírez-Escudero, Dr. J. Sanz-Aparicio* Macromolecular Crystallography and Structural Biology Department Institute of PhysicalChemistry Rocasolano (CSIC) Serrano 119, 28006 Madrid, Spain E-mail: xjulia@iqfr.csic.es

[c] M. Gimeno-Pérez, Prof. Dr. M. Fernández-Lobato Molecular Biology Department

Centre of Molecular Biology Severo Ochoa (CSIC-UAM) Autonomous University of Madrid, 28049 Madrid, Spain

[d] Dr. A. Poveda, Prof. Dr. J. Jiménez-Barbero

cCIC bioGUNE: Center for Cooperative Research in Biosciences Basque Network of Science Technology and Innovation; Biscay Science and Technology Park 801-A Ibaizabal Bidea St., Derio town 48160, Spain 


\section{ABSTRACT}

This work investigates the ability of the $\beta$-fructofuranosidase pXd-INV from the yeast Xanthophyllomyces dendrorhous to glycosylate the olive biophenol hydroxytyrosol (HT). Two fructosylated derivatives (Fru-HT1 and Fru-HT2) were synthesized. Under the best conditions ( $300 \mathrm{mg} / \mathrm{mL}$ sucrose, $25 \mathrm{mg} / \mathrm{mL} \mathrm{HT}$ ), the maximum yield was $45.6 \%$. MS and 2D-NMR analyses showed that the major product (Fru-HT1) was fructosylated at the primary OH of HT. The structure of the complexes with the substrates and the product analyzed by crystallography led to the understanding of the molecular determinants regulating the enzymatic mechanism. Productsoaked crystals revealed that the minor derivative (Fru-HT2) was fructosylated at the phenolic $p$ $\mathrm{OH}$ group. The two binding modes for HT at pXd-INV active site are governed almost exclusively by packing to Trp105 (Fru-HT1) and polar interactions with the loop Glu334-Asn342 (Fru-HT2), respectively. Specific mutagenesis at these residues was accomplished to tune the enzyme regiospecificity. One of the studied mutants (N342Q) was notably more specific for the fructosylation at the phenolic $\mathrm{OH}$ than the wild-type.

\section{INTRODUCTION}

Olive biophenols (tyrosol, hydroxytyrosol, oleuropein, etc.) have emerged in the nutraceutical and functional food markets due to their notable antioxidant activity and capacity to reduce the risk of cardiovascular diseases, as well as their protective effect against oxidative DNA damage.[1-3] Among them, hydroxytyrosol (HT, 3,4-dihydroxyphenyl ethanol) possesses the highest in vitro antioxidant activity[4-5] and displays anti-inflammatory, neuroprotective and antitumoral properties.[6-11] In fact, HT is the only polyphenol in the market that supports a European Food Safety Authority health claim. ${ }^{[12]}$ HT exhibits a poor bioavailability due to its fast transformation into sulphated and glucuronidated metabolites, whose biological activity remains unclear.[13-14]

The glycosylation of phenolic antioxidants is being exploited as a tool to improve their bioavailability, aqueous solubility and stability, among other properties. ${ }^{[5,15-18]}$ In fact, many polyphenols naturally occur as glycosides and glycoconjugates, in which the glycone moiety often exerts a great influence in their activity.[19] For example, the $\beta$-D-glucopyranoside of tyrosol (salidroside) is the main bioactive compound in Rhodiola species.[20-21] Glycosylation can increase the stability of the polyphenol during storage and gut transit after ingestion, acting as a kind of prodrug that finally releases the aglycone in our body.

The glycosylation of HT has been scarcely investigated, basically by the use of enzymatic catalysis. Trincone et al. reported the $\alpha$-glucosylation of HT using an $\alpha$-glucosidase from Aplysia fasciata. ${ }^{[22]}$ Recently, Nieto-Dominguez et al. achieved the $\beta$-xyloxylation of HT with a fungal $\beta$ xylosidase. ${ }^{[23]}$ The $\beta$-fructoside of HT was first synthesized by Potocka et al.[24] using a residual activity present in a commercial lactase. Glucuronidated metabolites of HT have been also synthesized by chemical methods in order to analyze their bioactive properties.[25-26] Interestingly, tyrosol and HT $\beta$-glucosides are structural cores of several phenylethanoid-based bioactive molecules present in medicinal plants.[27] 
Glycosidases (GHs, EC 3.2.1) catalyze the hydrolysis of di-, oligo- and polysaccharides but, under appropriate conditions, are able to synthesize different oligosaccharides ${ }^{[28-31]}$ and even to glycosylate non-sugar acceptors. ${ }^{[32-34]}$ Various GHs of families 32 and 68 have been successfully applied to the fructosylation of different organic compounds generating novel fructosylated conjugates. ${ }^{[35]}$

The $\beta$-fructofuranosidase Xd-INV from the basidiomycota yeast Xanthophyllomyces dendrorhous (formerly Phaffia rhodozyma) is a highly glycosylated enzyme of GH32 family that catalyzes the release of fructose from the nonreducing termini of various $\beta$-D-fructofuranoside substrates. However, it also catalyzes the synthesis of short-chain fructooligosaccharides (FOS) by transferring one or two fructosyl moieties to the sucrose skeleton.[36] Xd-INV is unique in its ability to transfer fructosyl moieties to the glucose unit of sucrose forming neo-FOS (neokestose and neonystose, ${ }^{6}$ G-FOS series). ${ }^{[37-38]}$ Moreover, we demonstrated that Xd-INV is also able to fructosylate a variety of carbohydrates containing glucose (including di- and trisaccharides such as maltose, isomaltose and maltotriose ${ }^{[39]}$ yielding novel hetero-fructooligosaccharides with potential applications in the functional food and pharmaceutical industries.

$\mathrm{Xd}-\mathrm{INV}$ is a dimeric protein with a molecular weight of $320-380 \mathrm{kDa}, 60-70 \%$ of which corresponds to N-linked carbohydrates. We reported the crystal structure of the native enzyme, which revealed that the glycan chains attached to two specific glycosylation sites are crucial for dimerization and activity.[40] Furthermore, the structural analysis of complexes of the inactive mutant (pXd-INV-D80A) with various short fructooligosaccharides acting as potential substrates or products uncovered the molecular basis of its broad substrate specificity, and pointed to the key role of some particular residues in the substrate binding. Thus, we found two alternative binding sites of the acceptor sucrose to form $\beta(2 \rightarrow 1)$ or $\beta(2 \rightarrow 6)$ linked products, explaining the formation of neokestose and 1-kestose, respectively.

A remarkable finding of our crystallographic analysis was the presence of a HEPES molecule in the crystals, coming from the buffer solution. ${ }^{[40]}$ This HEPES molecule was located in the active site next to a fructose unit, in an appropriate position that showed its potential as an acceptor. This observation suggested the idea of testing other compounds than sugars as putative acceptor substrates for $\beta$-fructose. In particular, the fructosylation of HT using Xd-INV was attempted due to the presence of a hydroxyethyl moiety linked to a six-membered ring similarly to HEPES.

Therefore, the goal of the present work was to evaluate the enzymatic fructosylation of HT catalyzed by recombinant Xd-INV expressed in Pichia pastoris (pXd-INV), [41] and to investigate the structural determinants ruling the process. Apart from its intrinsic bioactivity, HT fructosides could be employed as building blocks for the development of novel phenylethanoid derivatives with modified pharmacological properties.[24] This knowledge provides a valuable tool for the future design of efficient biocatalysts for the glycosylation of bioactive compounds by Xd-INV and other glycosidases. ${ }^{[42]}$ 


\section{RESULTS AND DISCUSSION}

\section{Fructosylation of hydroxytyrosol by pXd-INV}

It is well reported that the main transglycosylation products obtained from sucrose with native (Xd-INV) and recombinant (pXd-INV) $\beta$-fructofuranosidases from $X$. dendrorhous are the trisaccharides neokestose and 1-kestose. ${ }^{[36-37,41]}$ Additionally, this enzyme disclosed the ability to fructosylate other carbohydrates containing a glucose moiety such as maltose and maltotriose. ${ }^{39]}$ Moreover, the presence of a HEPES molecule in the crystals, ${ }^{[40]}$ mimicking the location of an acceptor for the fructose in a putative intermediate complex, suggested the possibility of testing other non-sugar compounds as acceptor substrates.

Thus, the ability of pXd-INV to fructosylate the phenolic phytochemical hydroxytyrosol (HT) was analyzed by using sucrose as fructosyl donor and HT as acceptor. Two fructosylated HT derivatives (Fru-HT1 and Fru-HT2), the first of them in higher proportion, were detected by HPLC at $280 \mathrm{~nm}$ using an amino column (Figure 1a). The higher retention time of these peaks compared with HT indicated that they were likely glycosides. We confirmed by HPAEC-PAD (Figure 1b) that the profile of synthesized FOS was not altered by the presence of HT. Neokestose and 1-kestose were the major transglycosylation products. Neonystose was not detected under the assayed conditions.
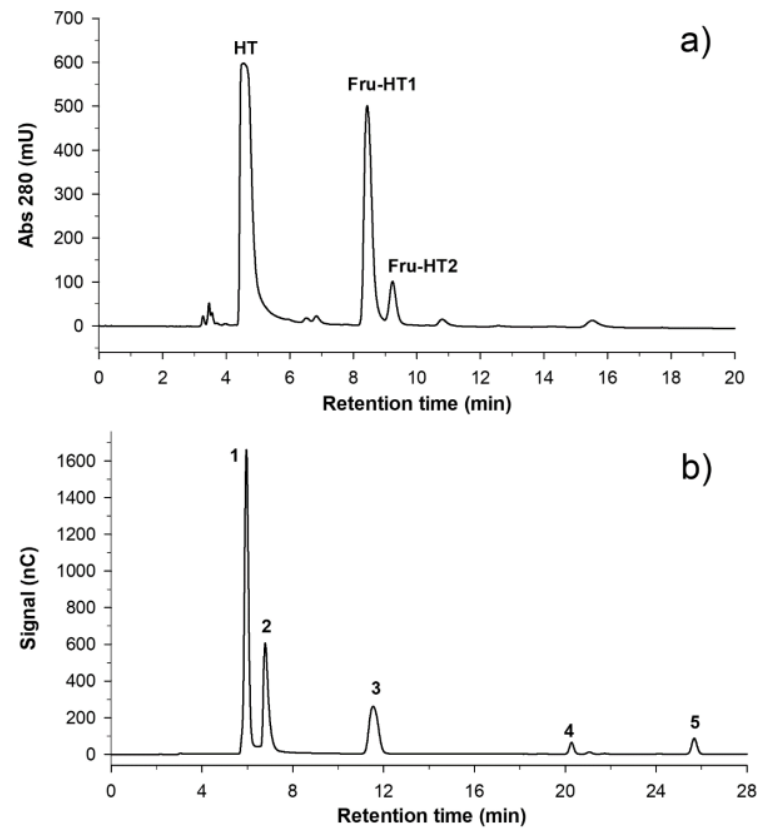

Figure 1. HPLC analysis of the reaction between sucrose $(300 \mathrm{mg} / \mathrm{mL})$ and hydroxytyrosol (25 $\mathrm{mg} / \mathrm{mL}$ ) catalyzed by $\beta$-fructofuranosidase pXd-INV. (a) Chromatogram using a NH2 column and PDA detector. HT: Hydroxytyrosol; Fru-HT1 and Fru-HT2: Fructosides of HT; (b) HPAEC-PAD chromatogram using a PA1 column. (1) Glucose; (2) Fructose; (3) Sucrose; (4) 1-Kestose; (5) Neokestose. 
Different concentrations of sucrose and HT were investigated to optimize the production of the fructosylated HT conjugates (Fru-HT1 and Fru-HT2). The results obtained are represented in Figure 2. At a fixed $100 \mathrm{mg} / \mathrm{mL}$ sucrose concentration, the yield of fructosylated compounds increased with the HT concentration in the $10-100 \mathrm{mg} / \mathrm{mL}$ range (Fig. 2a); however, when moving from $25 \mathrm{mg} / \mathrm{mL}$ to $100 \mathrm{mg} / \mathrm{mL}$ the production of Fru-HT only increased moderately (from 1.0 to $1.5 \mathrm{mg} / \mathrm{mL}$ ). Thus, considering both the product yield and the cost of hydroxytyrosol, $25 \mathrm{mg} / \mathrm{mL}$ was chosen as the optimum hydroxytyrosol concentration for further improvement.

Sucrose concentration was then assessed (in the range from 100 to $600 \mathrm{mg} / \mathrm{mL}$ ). As shown in Fig. $2 \mathrm{~b}$, the best results were reached using $300 \mathrm{mg} / \mathrm{mL}$ sucrose (yielding nearly $11.7 \mathrm{mg} / \mathrm{mL}$ of fructosides in $6 \mathrm{~h}$ ). At higher sucrose concentrations, the reaction was directed preferably towards the formation of fructooligosaccharides (data not shown).

Based on the previous screening, the fructosylation of HT was studied under the optimal conditions (25 mg/mL HT and $300 \mathrm{mg} / \mathrm{mL}$ sucrose) to determine the maximum yield of glycosylated products. Figure 3 represents the formation of Fru-HT1 and Fru-HT2 with regards the consumption of sucrose. The maximum yield $(45.6 \%, 11.1 \mathrm{mg} / \mathrm{mL}$ of Fru-HT1 and $0.2 \mathrm{mg} / \mathrm{mL}$ of Fru-HT2) was obtained when approximately $80 \%$ of the initial sucrose had been consumed. The Fru-HT1 was only hydrolyzed when the availability of sucrose decreased considerably (less than $5 \%$ of the initial amount). At the end of the process, the Fru-HT1 had almost disappeared. This is the typical product profile in kinetically controlled processes catalyzed by glycosidases, in which the substrate and the product finally compete for the nucleophilic attack of water. ${ }^{[43-44]}$ Although its concentration was notably lower, the Fru-HT2 was more resistant to hydrolysis than Fru-HT1. The profile of FOS formation was similar to that of Fru-HT1 (Fig. 3), in accordance with previous works with this enzyme. ${ }^{[38,41]}$. 

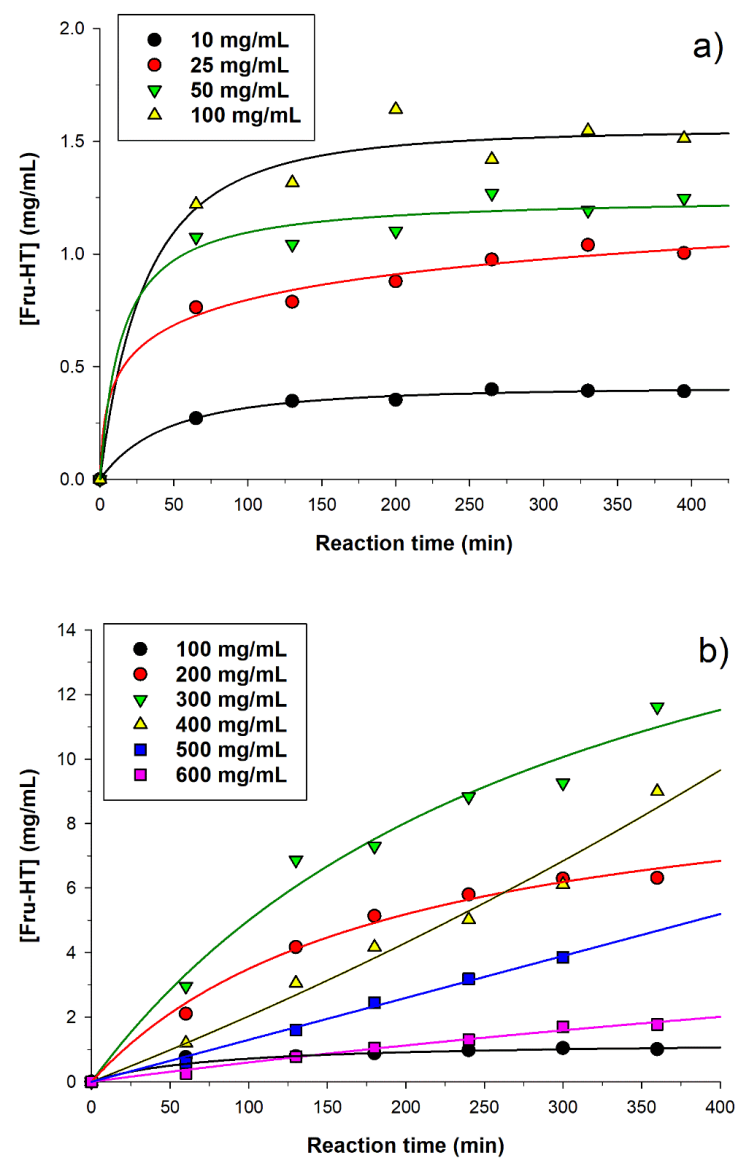

Figure 2. Production of fructosylated hydroxytyrosol (Fru-HT1 + Fru-HT2) by pXd-INV (a) Effect of the concentration of HT fixing the sucrose concentration $(100 \mathrm{mg} / \mathrm{mL})$; (b) Effect of sucrose concentration fixing the concentration of HT $(25 \mathrm{mg} / \mathrm{mL})$. Concentration of HT and sucrose are indicated in the corresponding panels.

The major fructosylated derivative (Fru-HT1) was purified using semipreparative HPLC and analyzed by ESI-TOF mass spectrometry. A peak of $339 \mathrm{Da}\left(\mathrm{M}+\mathrm{Na}^{+}\right)$was detected (see Fig. S1 in Supplementary Information). A combination of 1D and 2D NMR techniques was used to characterize the compound (see Table 1 and Figs. S2-S8 in Supporting Information). The studied sample resulted to be an almost 50:50 mixture of unreacted HT and Fru-HT1, with one impurity, which was identified as citrate. Although the signals of both compounds were found to be very similar, the use of 1D-selective techniques (1D-TOCSY, 1D-NOESY) and high magnetic field (800 $\mathrm{MHz}$ ) allowed us to identify each set of signals and to characterize them separately. Finally, the glycosidation position was identified by employing HMBC correlation experiments. 


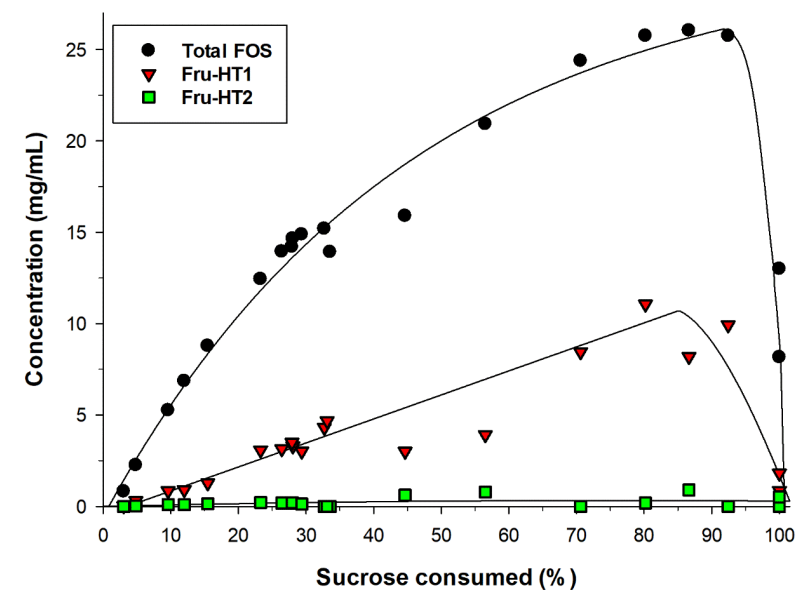

Figure 3. Production of fructosylated hydroxytyrosol and FOS by pXd-INV under the optimal reaction conditions $\left(300 \mathrm{mg} / \mathrm{mL}\right.$ sucrose, $25 \mathrm{mg} / \mathrm{mL} \mathrm{HT}, 100 \mathrm{mM}$ sodium acetate $\mathrm{pH} 5.0,60^{\circ} \mathrm{C}$ ) with regards to the consumption of sucrose.

In particular, a cross peak between one of the methylene "Ha" protons and the quaternary $\mathrm{C} 2$ of the fructose moiety was found. Strikingly, the H4' and H6' of fructose showed unusual high-field chemical shifts (more than $0.5 \mathrm{ppm}$ upfield shifting with respect to regular fructose or other derivatives).[44] Thus, standard molecular mechanics calculations were performed to obtain a three-dimensional model of the molecule. The global minimum structure is in full accordance with the experimental data. In fact, the fructose moiety is stacked with the aromatic ring of HT, stabilized by $\mathrm{CH}-\pi$ interactions, as frequently found in protein-glycan complexes.[45-46] Thus, the observed shielding for H4 and H6-6', highly affected by the aromatic $\pi$ cloud, can be explained. Moreover, the observed NOEs between one H6 and the aromatic protons of HT moiety is also accounted for by the global minimum structure (Fig. S9 in Supporting Information). In conclusion, the synthesized product was characterized as 3,4-dihydroxyphenyl)ethyl $\beta$-D-fructofuranoside, which was first described by Potocká et al. ${ }^{24}$ 
Table 1. NMR Spectroscopic Data (800 MHz, D20, 298K) for compound Fru-HT1.

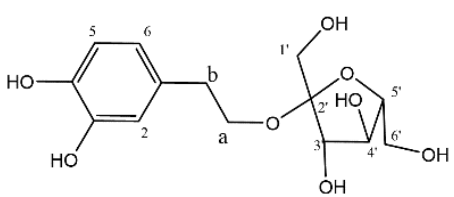

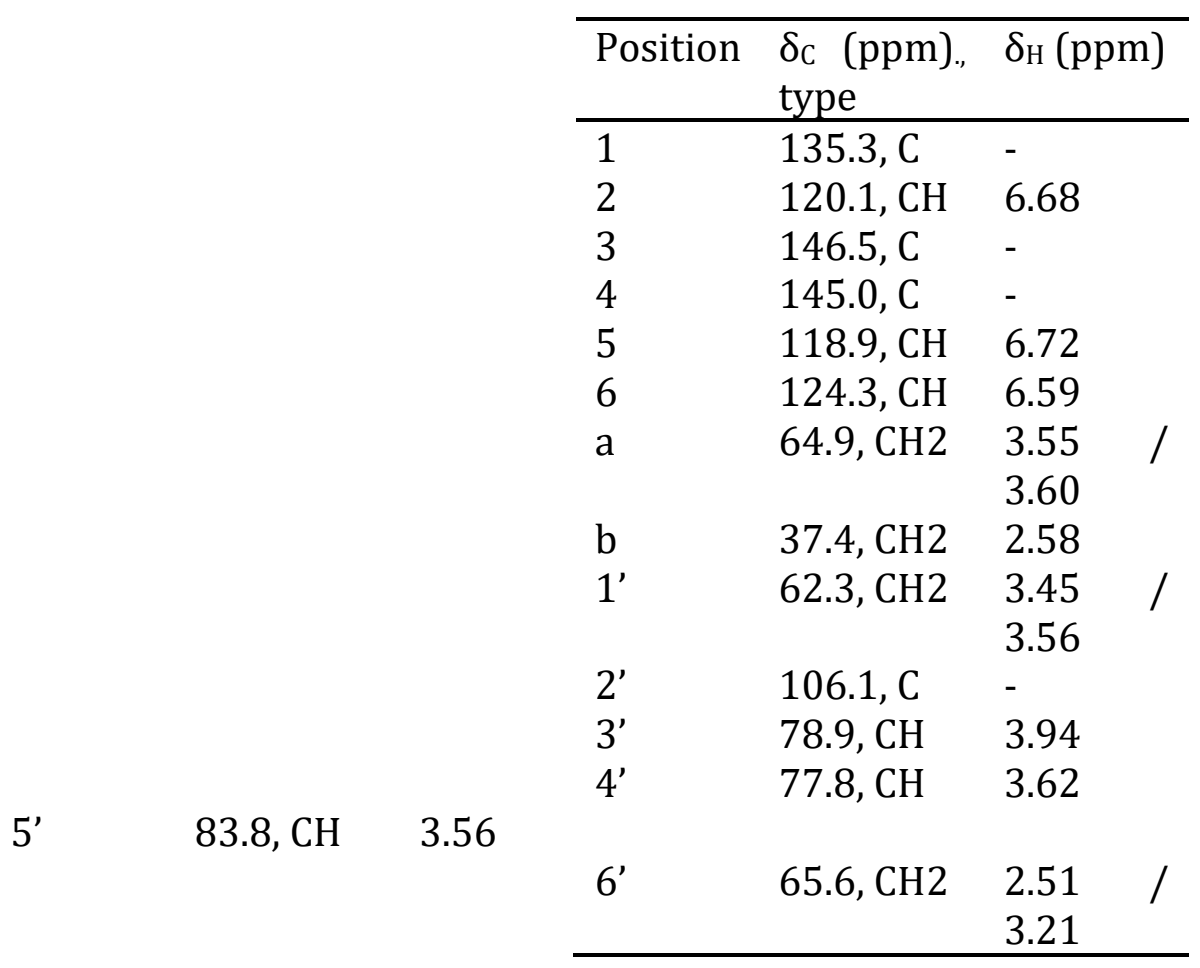

\section{Structural and molecular analysis of hydroxytyrosol as acceptor of pXd-INV}

To unclose the molecular basis of the enzymatic reaction, crystals from the inactivated pXdINV-D80A mutant were soaked into $\beta$-fructose and HT, to obtain the ternary intermediate complex with both substrates, and also with the purified Fru-HT1. The experimental details of the crystal structure determination of both complexes are given in Table S1 (Supporting Information). Both crystals showed clear electron density at the active site, as shown in Figure 4, which allowed unambiguous modelling of the bound molecules.

In the ternary intermediate complex (Fig. 4a), $\beta$-fructose occupies subsite -1 in a position conserved with that previously described.[40] Interestingly, there are two hydroxytyrosol molecules (HT1 and HT2 in the figure) that are located in positions appropriate to act as potential acceptors of $\beta$-fructose, as both substrates present $\mathrm{OH}$ groups in the proximity of the fructose $\mathrm{C} 2$ to make the glycosidic linkage. Thus, HT2 presents one of its phenolic hydroxyls located $3.5 \AA$ from the fructose $\mathrm{C} 2$, which is a proper distance for the nucleophile attack to proceed. On the other hand, HT1 locates its primary $\mathrm{OH}$ group oriented towards this $\mathrm{C} 2$ atom, although at a 
slightly higher distance. Nevertheless, the position of HT1 is in agreement with the main fructosylated product identified from the reaction (Fru-HT1), while that of HT2 can represent a second binding mode of the acceptor substrate producing a different fructosylated derivative, which could explain the minor peak observed in the HPLC analysis (Fig. 1a). Finally, there is a third hydroxytyrosol molecule bound at the active site (HT3) that is located too far from the fructose to represent a productive binding mode.

With respect to the product-soaked crystals (Fig. 4b), they show a molecule of fructosylhydroxytyrosol located at the active site (Fru-HT1), with the fructose moiety occupying the -1 subsite similarly to the ternary complex. This molecule corresponds to the derivative fructosylated at the primary $\mathrm{OH}$ hydroxyl group, identified as the main product of the reaction. Unexpectedly, a second molecule trapped at the active site (Fru-HT2) presents an electron density that clearly corresponds to a different derivative fructosylated at the phenolic $p$-OH group, which is compatible with the binding mode of HT2 described above and is likely the minor product that was not fully resolved by semipreparative HPLC chromatography.

a)

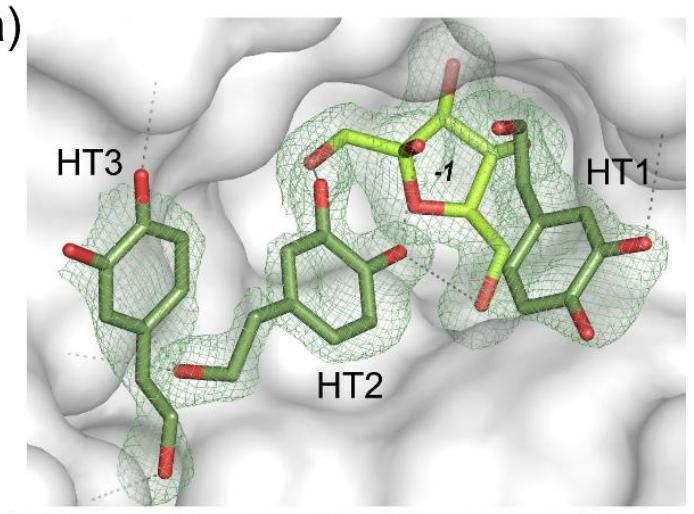

b)

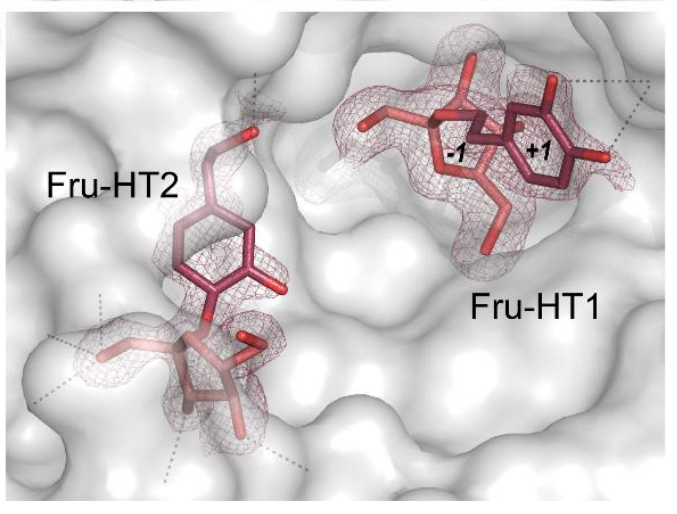

Figure 4. Surface representation of the pXd-INV-D80A mutant showing the molecules bound at its active site. (a) Crystals soaked in $\beta$-fructose (light green) and HT (green); three different positions are labelled as HT1, HT2 and HT3. (b) Crystals soaked in the transglycosylation product (fructose moiety, light red; HT, red) purified by HPLC. Fru-HT1 is the major product identified by NMR, and corresponds to the product that would be formed from HT bound at the HT1 binding site, while Fru-HT2 would be produced by fructosylation of HT at HT2 position. The 2Fo-Fc electron density maps are contoured at $1 \sigma$. 
A detailed view of the precise ligand binding in both complexes is shown in Fig. 5. In the ternary complex (Fig. 5a), HT1 is bound by stacking its aromatic ring against Trp105; interestingly, this hydrophobic contact is the driving force directing sucrose binding in the catalytic pocket as to make neokestose, the main transfructosylation product of Xd-INV.[40] This feature is in agreement with a preferred binding of hydroxytyrosol at HT1 position with the concomitant production of the observed major derivative.Furthermore, this primary $\mathrm{OH}$ group is linked to the catalytic Glu303 carboxylate through a water molecule, which is consistent with the hydroxyl activation in the second step of the reaction to make the nucleophile attack. HT1 is further stabilized in this position through polar interaction of one of its phenolic OHs with Leu170 main-chain, from loop Ser166-Thr180, which is involved in defining subsite +1 .

a)

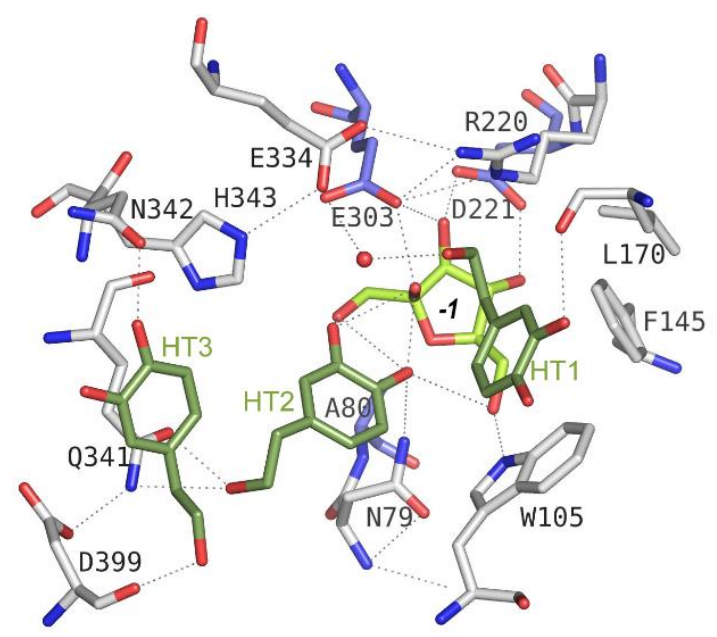

b)

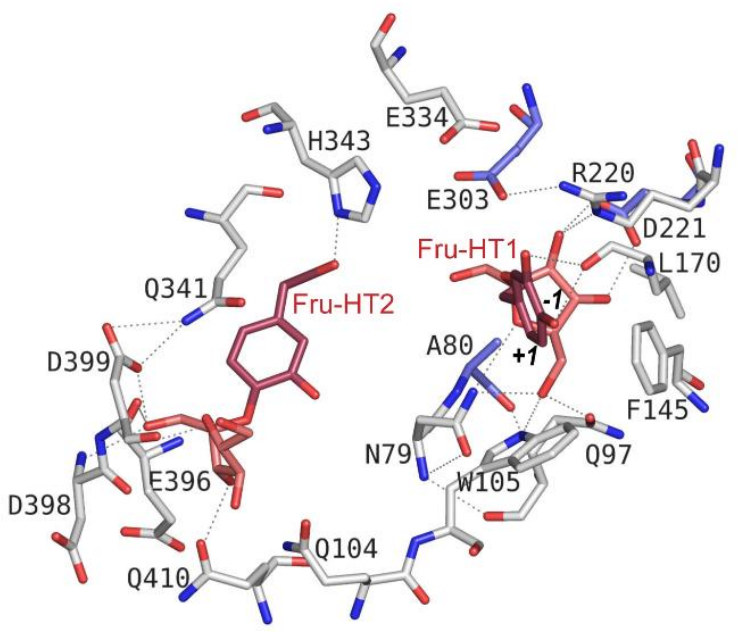

Figure 5. Detail of the atomic interactions produced at the Xd-INVD80A active site in the crystals soaked into: (a) fructose (light green) and HT (green); (b) the fructosylated product (light red and red). The catalytic residues (D80A and E303) are highlighted in blue. 
With respect to HT2, the molecule is recognized by polar interactions to fructose, which keeps the precise orientation of the phenolic $\mathrm{OH}$ to perform nucleophile attack, and by interaction of its flexible aliphatic chain with Gln341, from loop Glu334-Asn342, which was previously described to play a key role in sucrose binding to make inulin-type $\beta(2 \rightarrow 1)$ linkages. ${ }^{[0]}$ This loop is defining a polar pocket in which HT3 is accommodated by stacking against Gln341 side chain and through hydrogen bonds to Asn342 and Asp399.

Fig. $5 \mathrm{~b}$ shows a detail of the binding of the fructosylated derivatives at the active site. Fru-HT1 is occupying subsites -1 and +1 in an expected substrate/product-binding mode, with its aromatic moiety being stabilized by polar interaction to Leu170 main-chain from loop Ser166-Thr180. By contrast, Fru-HT2 is bound at a non-catalytically relevant position in a pocket generated by a shift in the Gln341 side-chain, in which its aromatic portion is hydrogen linked to His343, from the same loop, whilst the fructose ring is stabilized by many polar interactions to several residues shown in the figure. As it occurs with HT3 molecule in the ternary complex, this position may not represent a relevant product binding mode but, rather, seems to be an artefact of the crystallization step. Interestingly, binding of the derivative to this secondary position allows the unambiguous molecular identification of the observed minor product.

\section{Implications for the specificity mechanism}

Our analysis shows that the fructosylation of hydroxytyrosol gives two different derivatives, in a reaction that occurs as given in Fig. 6. Furthermore, from the direct comparison of the different complexes, the main features governing the transglycosylation mechanism of hydroxytyrosol by pXd-INV can be depicted. Fig. 7 displays different details of the structural comparison between the crystals soaked into the substrates and the products. In the first step of the reaction, hydroxytyrosol preferably binds to the HT1 site, mostly directed by hydrophobic contact to Trp105 (Fig. 7a), which seems the driving force directing HT binding. In the crystal, the primary $\mathrm{OH}$ group of HT1 is connected to the acid-base catalyst Glu303 and Glu334 through water molecules. Only a small adjust of the aliphatic chain torsions is needed to locate this hydroxyl at reactive distance from the $\mathrm{C} 2$ atom while keeping interaction with Glu303, which guarantees the ulterior activation of the $\mathrm{OH}$ to perform the nucleophilic attack to the fructose (Fig. 7a). The long and flexible side-chain of the two glutamates would permit the correct positioning of the hydroxyl to yield the major observed product. In agreement with this role, the structural comparison of both complexes shows conformational changes at Glu303 and Glu334 side-chains. 


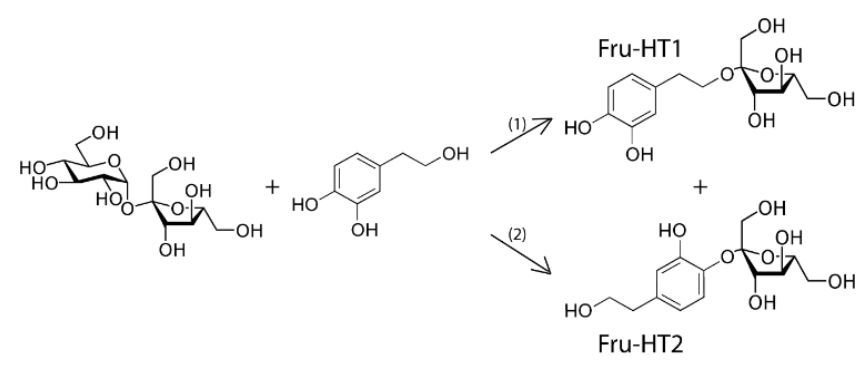

Figure 6. Scheme of the fructosylation reaction of HT by pXd-INV. Fru-HT1: major product identified by NMR; Fru-HT2: minor product detected by crystallography.

a)

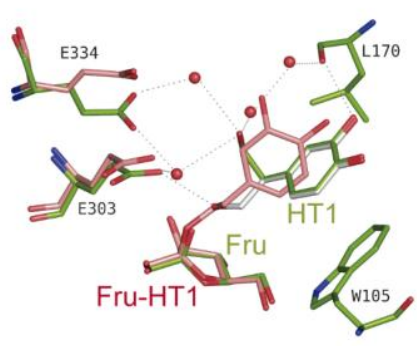

$\mathbf{L}^{\mathrm{A} 80}$ b)

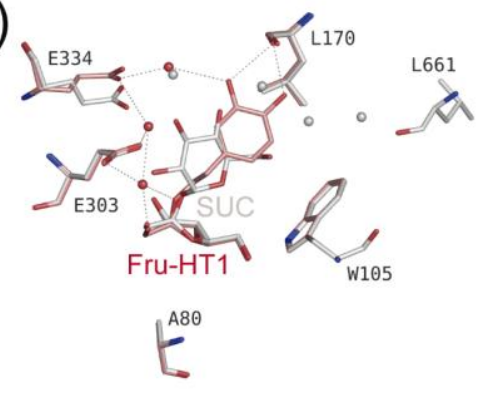

c)

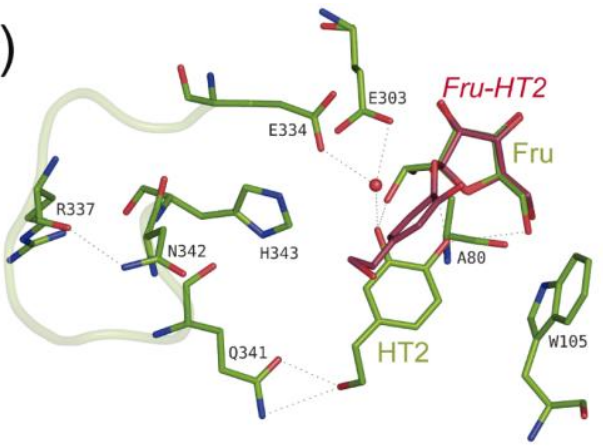

Fig. 7. Comparison of the substrates/product complexes. (a) A detail of the structural superimposition of the ternary substrates complex (light green) onto the major product complex (salmon) showing relevant residues involved in HT1 binding. Only the residues changing its conformation in the product complex are shown. A modelled HT1 (white) locates the primary OH at a reactive position for nucleophylic atack to fructose. (b) Structural superimposition of the major product complex (salmon) onto the reported Xd-INV complex with sucrose (white) (PDB code 5FIX). The polar links to the product Fru-HT1 are shown. (c) A detail of HT2 binding site (light green) with a putative Fru-HT2 product binding mode. The coordinates for Fru-HT2 found in the crystal have been manually docked at subsite -1 (red).

A remarkable issue observed in our study is the fact that this fructosylated product appears to be a bad substrate for pXd-INV (Fig. 3) and the effective hydrolysis of Fru-HT1 is only observed when the remaining sucrose in the reaction is negligible. Fig. $7 \mathrm{~b}$ shows the comparison of the crystallographic complex of the major fructosylated HT product, here reported, to that solved before for Xd-INV with sucrose. ${ }^{[40]}$ As seen in the figure, Fru-HT1 is occupying subsite -1 similarly to sucrose and, in principle, it could be degraded by Xd-INV. However, some subtle differences may be detected at subsite +1 . Thus, the glucose from sucrose is linked to Glu334, Leu170 and Leu661 through a net of water molecules, which may well constitute a plastic network that allows the conformational changes of fructose required to form the different intermediates along the catalytic mechanism. By contrast, the phenolic OHs of Fru-HT1 are directly hydrogen linked to Leu170 main-chain, and this could possibly fix a conformation that hinders the necessary molecular flexibility of fructose slowing hydrolysis. Indeed, other explanations cannot be 
excluded, as the possibility that the primary alcohol may be a less efficient leaving group making the reaction too slow.

With regard to the second hydroxytyrosol binding mode found in this study, HT2 is bound mostly through polar interaction to Glu341, from loop Glu334-Asn342, and to the OH groups of fructose, as said before. Moreover, the putative position of the resulting product can be modelled by superimposition of the fructose moiety from Fru-HT2, as found in the crystal, onto the fructose bound at subsite -1 . As it is shown in Fig. 7c, and even assuming some internal molecular flexibility, this secondary product would be most likely allocated by interacting with the loop Glu334-Asn342, which seems to be determinant for producing this secondary derivative.

\section{Site-directed mutagenesis of pXd-INV}

As stated before, there are two alternative binding modes for hydroxytyrosol at pXd-INV-D80A active site, which are governed almost exclusively by, either, packing to Trp105 or polar interactions to the loop Glu334-Asn342. Consequently, a specific mutagenesis at these precise residues (e.g. Trp105, Gln341) could potentially modify the transfructosylating activity of pXdINV and possibly determine the fructosylated product selectivity.

In this context, we made the mutant Xd-INV-W105F, which generates an enzyme practically unable of hydrolyzing sucrose under the conditions used for Fru-HT production. This result demonstrates the key role of this tryptophan in the enzyme machinery (data not shown).

Therefore, we focused our efforts on changes at the residues belonging to the loop Glu334Asn342, with the aim of modulating the selectivity towards a specific fructosylated derivative. This is a very flexible loop that is rather disordered in the free enzyme and is stabilized in the complexes by making crucial interactions with the substrates. In particular, we investigated changes in Gln341 and Asn342, two residues clearly protruding into the catalytic pocket and that had revealed evident conformational variability in the complexes. Preliminary results showed that the transfructosylation profiles of two mutants, Q341S and N342Q, presented significant differences compared with the wild-type. These variations were analyzed in detail. Figure 8 represents the formation of Fru-HT1, Fru-HT2 and total FOS as a function of sucrose conversion. 

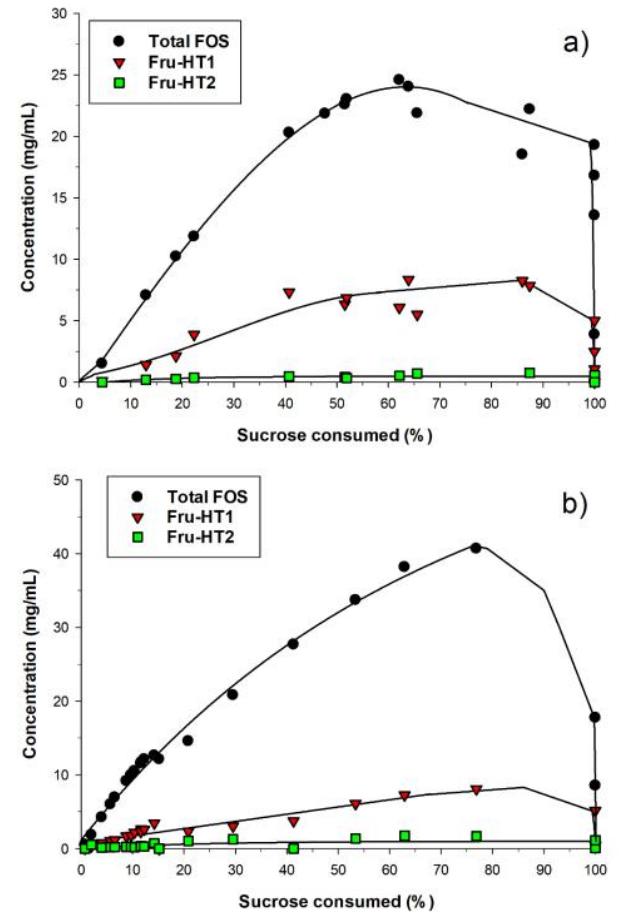

Figure 8. Production of fructosylated hydroxytyrosol derivatives under the optimal reaction conditions $\left(300 \mathrm{mg} / \mathrm{mL}\right.$ sucrose, $25 \mathrm{mg} / \mathrm{mL} \mathrm{HT}, 100 \mathrm{mM}$ sodium acetate $\mathrm{pH} 5.0,60^{\circ} \mathrm{C}$ ) as a function of sucrose conversion, using the mutants: (a) pXd-INV-Q341S and (b) pXd-INV-N342Q.

As occurred with the wild-type enzyme (Fig. 3), the maximum yield of fructosylated derivative obtained with the two mutants was achieved when approximately $10-20 \%$ of the initial sucrose remained in the reaction. However, the main difference between the wild-type and the mutants was the ratio between Fru-HT1 and Fru-HT2 (Table 2). The maximum yield of Fru-HT1 was slightly lower with the two mutants than with the wild-type. In contrast, the mutant N342Q was more specific for the fructosylation at the phenolic $p$-OH than the wild-type. This effect also took place with the mutant Q341S, but at lower extent. Although the precise contribution of these two residues in substrate/product binding is difficult to decipher, these results highlight the key role of loop Glu334-Asn342 in the enzymatic mechanism and, therefore, its direct implication in modulating the reaction specificity.

In addition, and regarding the formation of FOS, it is worth noting that the mutant N342Q gives rise to a higher yield compared with the wild-type and the mutant Q341S (Table 2). The side-chain of Asn342 is making a polar link with Arg337 carbonyl (Fig. 7c) and, therefore, contributes to the internal stabilization and topology of loop Glu334-Asn342. Therefore, the Asn to Gln replacement may produce a rearrangement of the loop influencing molecular dynamics, which could result in the observed increase of FOS production. 
Table 2. Maximum production of the fructosylated HT derivatives (and total FOS at this point) by pXd-INV and its mutants.

\begin{tabular}{lcccc}
\hline Enzyme & $\begin{array}{c}{[\text { Fru- }} \\
\text { HT1 }] \\
(\mathrm{mg} / \mathrm{mL})\end{array}$ & $\begin{array}{c}{[\text { Fru- }} \\
\text { HT2 }] \\
(\mathrm{mg} / \mathrm{mL})\end{array}$ & $\begin{array}{c}\text { Ratio } \\
\text { HT1/HT2 }\end{array}$ & $\begin{array}{c}{[\mathrm{FOS}]} \\
(\mathrm{mg} / \mathrm{mL})\end{array}$ \\
\hline $\begin{array}{l}\text { Wild- } \\
\text { type }\end{array}$ & 11.1 & 0.18 & 61.7 & 25.7 \\
Q341S & 7.9 & 0.76 & 10.4 & 22.2 \\
N342Q & 8.1 & 1.70 & 4.8 & 40.7 \\
\hline
\end{tabular}

\section{CONCLUSIONS}

The development of robust and efficient biocatalysts for the synthesis of novel bioactive compounds is a challenging task to take full advantage of biotechnological processes. This work focuses on the $\beta$-fructofuranosidase Xd-INV, a hydrolytic enzyme with broad transfructosylating acceptor specificity, which contains a promiscuous active-site able to accommodate other substrates than sugars. Our previous observation of small molecules containing a six-membered ring (from the buffer) trapped in the catalytic pocket of the protein crystals, suggested us to try potential glycosylation acceptors based on a phenolic core, which could include other hydroxyl groups. With this aim, we selected hydroxytyrosol, a phenolic compound with marked antioxidant and bioactive properties.

The fructosylation of HT using recombinant Xd-INV gave rise to two compounds, detected by HPLC. The major product was purified and identified by NMR as the primary alcohol derivative. We undertook a detailed structural characterization of the enzymatic mechanism by analyzing the complexes with the substrates and the products, which led to the unambiguous identification of the two Fru-HT derivatives, the minor product corresponding to the fructoside in the phenolic $p$ $\mathrm{OH}$ group. Interestingly, this analysis disclosed various specific residues that are essential to direct HT binding to two alternative sites modulating the reaction selectivity. Moreover, preliminary results showed an altered profile of derivatives in some mutants. Therefore, this finding gives a valuable tool to tune the enzyme regiospecificity.

Further design by protein engineering may expand the range of substrates available for this enzyme, which could provide additional fructosyl derivatives. This approach has been successfully applied by other groups $[32,42,47]$ and could improve the potential of pXd-INV for biotechnological applications. The synthesized HT fructosides could be also employed as core structures for designing analogues of biologically active phenylethanoid derivatives found in medicinal plants. 


\section{EXPERIMENTAL SECTION}

\section{Production of recombinant $\beta$-fructofuranosidase (pXd-INV)}

The $\beta$-fructofuranosidase from Xanthophyllomyces dendrorhous ATCC MYA-131 (Xd-INV) was expressed in Pichia pastoris as previously reported.[41] Basically, the gene Xd-INV (GenBank accession no. FJ539193.2) fused to the Saccharomyces cerevisiae MF $\alpha$ secretion signal sequence was cloned in plasmid pIB4 (construction QDNS-pIB4) and included in P. pastoris. Transformants were grown in $50 \mathrm{~mL}$ of BMG $\left(1.34 \%\right.$ yeast nitrogen base without amino acids, $4 \times 10^{-5} \%$ biotin, $1 \%$ glycerol, $50 \mathrm{mM}$ potassium phosphate $\mathrm{pH} 6.0$ ) during $24 \mathrm{~h}$ and then induced in $400 \mathrm{~mL}$ of BMM (same as BMG but $0.5 \%$ methanol instead of glycerol) for $35 \mathrm{~h}$ (about $21 \mathrm{U}$ of $\beta$ fructofuranosidase per $\mathrm{mL}$ of culture). The extracellular $\beta$-fructofuranosidase activity was purified using tangential concentration and DEAE-Sephacel chromatography. Active fractions were concentrated using Microcon YM-10 (Amicon) filters $(0.7 \mathrm{~mL} ; 4220 \mathrm{U} / \mathrm{mL} ; 5.8 \mathrm{mg} / \mathrm{mL})$ and stored at $-70^{\circ} \mathrm{C}$.

\section{Mutagenesis of $\mathbf{p X d}$-INV $\beta$-fructofuranosidase}

The inactive pXd-INV protein (Xd-INV-D80A) was obtained using site-directed mutagenesis by substitution of the residue acting as nucleophile in the enzyme catalytic mechanism. This mutant protein was expressed in P. pastoris following a described procedure, ${ }^{[40]}$ purified and concentrated as above $(0.32 \mathrm{~mL} ; 4.2 \mathrm{mg} / \mathrm{mL})$.New mutagenic variants of pXd-INV with substitutions W105F, Q341S and N342Q were obtained using plasmid QDNS-pIB4 as template and the following primers (substitution in bold): W105F(+): ATTCAGTTTGGAAACATCTCTCAGGGAGC; $\quad$ W105F(-): GATGTTT CCAAACTGAATGTGCTTTGGG; Q341S(+): CACTCTAACCATT GGCCTCTCTGG; Q341S(-): GTTAGAGTGATCGGCTCGTCCTTG; N342Q(+): CGATCACCAGCAACATTGGCCTCTCTG, N342Q(-): CCAATGTTGCTGGTGATCGGCTCG. All mutagenesis were verified by DNA sequencing and the resulting constructions included in P. pastoris. Protein expression was induced using methanol and the resulting pXd-INV variants purified as earlier referred.[40] Purity of the proteins was evaluated by SDS-PAGE (8\%).

\section{Standard $\beta$-fructofuranosidase activity assay}

$\beta$-Fructofuranosidase standard activity was determined by detection of reducing sugars with a modified 3,5-dinitrosalicylic acid (DNS) method adapted to a 96-well microplate scale.[48] The reaction mixture $(50 \mu \mathrm{L})$ contained $100 \mathrm{mg} / \mathrm{mL}$ sucrose in $100 \mathrm{mM}$ sodium acetate buffer $(\mathrm{pH}$ $5.0)$ and the enzyme solution $(5 \mu \mathrm{L})$, conveniently diluted to fit into a D-glucose calibration curve, was incubated at $60{ }^{\circ} \mathrm{C}$ for $20 \mathrm{~min}$. One unit of activity (U) corresponded to the release of one $\mu \mathrm{mol}$ of reducing sugars per minute.

\section{Fructosylation of hydroxytyrosol and optimization of reaction conditions}

The production of fructosyl-hydroxytyrosol (Fru-HT) by $\beta$-fructofuranosidase pXd-INV was studied in $1 \mathrm{~mL}$ reaction mixtures containing $0.14 \mathrm{U} / \mathrm{mL}$ of pXd-INV (or its mutants W105F, Q341S and N342Q) using $100 \mathrm{mM}$ sodium acetate $\mathrm{pH} 5.0$ as reaction buffer. Initially, sucrose concentration was set at $100 \mathrm{mg} / \mathrm{mL}$ and HT (Seprox Biotech) was used in the range of 10-100 
$\mathrm{mg} / \mathrm{mL}$. In another set of experiments, HT concentration was maintained at $25 \mathrm{mg} / \mathrm{mL}$ and sucrose was varied from 100 to $600 \mathrm{mg} / \mathrm{mL}$. Reactions were incubated at $60^{\circ} \mathrm{C}$ with orbital stirring. Aliquots (10-50 $\mu \mathrm{L}$ ) from the reaction mixtures were taken at different times, inactivated by enzyme denaturation at $96^{\circ} \mathrm{C}$ during $16 \mathrm{~min}$, and analyzed by HPLC.

\section{HPLC analysis}

The fructosylation of HT was followed by HPLC using a quaternary pump (Agilent Technologies, model 1100) coupled to a Phenomenex Luna-NH2 column $(250 \times 4.6 \mathrm{~mm}, 5 \mu \mathrm{m})$ with a photodiode array detector (PDA, Varian Prostar). Column temperature was kept at $30^{\circ} \mathrm{C}$ and flow rate at $1.0 \mathrm{~mL} / \mathrm{min}$. Each injection had a volume of $10 \mu \mathrm{L}$ and the analytes were eluted with a mixture $\mathrm{CH}_{3} \mathrm{CN}: \mathrm{H}_{2} \mathrm{O}$ 82:18 $v / v$. Integration of peaks was carried out using the Varian Star LC workstation 6.41 .

Sugars were analyzed by High Performance Anion-Exchange Chromatography with Pulsed Amperometric Detection (HPAEC-PAD) with a Dionex ICS3000 system and a CarboPack PA-1 column ( $4 \times 250 \mathrm{~mm}$ ) connected to a PA-1 guard column. Column temperature was kept at $30^{\circ} \mathrm{C}$. The starting mobile phase was $30 \mathrm{mM} \mathrm{NaOH}$ at $1 \mathrm{~mL} / \mathrm{min}$, and a gradient from $30 \mathrm{mM}$ to $100 \mathrm{mM}$ $\mathrm{NaOH}$ was performed in $20 \mathrm{~min}$. Then, the concentration of sodium acetate was increased from 0 to $72 \mathrm{mM}$ in $6 \mathrm{~min}$, and these conditions were maintained for $4 \mathrm{~min}$. Eluents were degassed by flushing with helium and peaks were analyzed using Chromeleon software.

\section{Purification of fructosyl-hydroxytyrosol}

The main fructosyl-hydroxytyrosol derivative (Fru-HT1) was purified using semipreparative HPLC with a quaternary pump (Agilent Technologies, model 1100) and a Kromasil amino column (250 x $10 \mathrm{~mm}, 5 \mu \mathrm{m})$. A three-way flow splitter (Accurate, LC Packings), a photodiode array detector (PDA, Varian Prostar) and an evaporative light scattering detector (ELSD, Alltech 2000ES) were used. ELSD conditions were set at $85^{\circ} \mathrm{C}$ and a nitrogen flow of $2.2 \mathrm{~L} / \mathrm{min}$. Each injection had a volume of $50 \mu \mathrm{L}$. Acetonitrile/water 82:18 v/v was used as mobile phase at 5.0 $\mathrm{mL} / \mathrm{min}$ for $6 \mathrm{~min}$. Acetonitrile percentage was kept at $60 \%$ for $4 \mathrm{~min}$. Then, it was changed back to $82 \%$ and maintained for $9 \mathrm{~min}$. The column temperature was kept at $30^{\circ} \mathrm{C}$. After collecting the Fru-HT1, the mobile phase was eliminated by rotary evaporation in a R-210 rotavapor (Buchi). The isolated product was characterized by mass spectroscopy and NMR.

\section{Mass spectrometry}

The molecular weight of the main fructosylated HT derivative was assessed using a mass spectrometer with hybrid QTOF analyzer (model QSTAR, Pulsar, AB Sciex). The sample was analyzed by direct infusion and ionized by electrospray (with methanol as ionizing phase) in positive reflector mode.

\section{NMR analysis}

The structure of the fructosylated derivative Fru-HT1 was determined using a combination of 1D (1H, 1D-selective NOESY experiments) and 2D (COSY, NOESY, DEPT-HSQC, HSQC-TOCSY, HMBC,) NMR techniques. The spectra of the sample, dissolved in deuterated water (ca. $10 \mathrm{mM}$ ), were recorded on a Bruker AVIII 800 spectrometer equipped with a TCI cryoprobe with gradients in 
the $\mathrm{Z}$ axis, at a temperature of $25^{\circ} \mathrm{C}$. Chemical shifts were expressed in parts per million with respect to the $0 \mathrm{ppm}$ point of DSS (4-dimethyl-4-silapentane-1-sulfonic acid), used as internal standard. All the pulse sequences were provided by Bruker. For the DEPT-HSQC and HSQC-TOCSY experiments, values of $7 \mathrm{ppm}$ and $2 \mathrm{~K}$ points, for the $1 \mathrm{H}$ dimension, and $120 \mathrm{ppm}$ and 256 points for the 13C dimension were used. For the HMBC experiments, values of $7 \mathrm{ppm}$ and $2 \mathrm{~K}$ points, for the $1 \mathrm{H}$ dimension, and $170 \mathrm{ppm}$ and 384 points for the $13 \mathrm{C}$ dimension were used. For the homonuclear experiments COSY and NOESY, $7 \mathrm{ppm}$ windows were used with a $2 \mathrm{~K} \times 256$ point matrix. For the NOESY and 1D-selective NOESY experiments, mixing times of 500-600 ms were used.

\section{Crystallization and $\mathrm{X}$-ray structure determination}

The inactive mutant pXd-INV-D80A was deglycosylated and crystallized as described before.[49] The ternary complex was obtained by soaking crystals in precipitant solution $(1.3 \mathrm{M}$ sodium citrate) supplemented with $20 \mathrm{mM}$ fructose (Sigma) for $10 \mathrm{~min}$, followed by $30 \mathrm{~min}$ immersion in precipitant solution plus $300 \mathrm{mM} \mathrm{HT}$. Xd-INV-D80A complexed with the fructosylation product was achieved by a 2-5 hour soaking in the precipitant solution supplemented with $30 \mathrm{mM}$ fructosyl-hydroxytyrosol (obtained as described in Section 2.6).

For data collection, pXd-INV-D80A crystals were transferred to cryoprotectant solutions consisting of mother liquor plus $10 \%(\mathrm{v} / \mathrm{v}$ ) ethylene glycol before being cooled in liquid nitrogen. Diffraction data were collected using synchrotron radiation on the XALOC beamline at ALBA (Cerdanyola del Vallés, Spain). Diffraction images were processed with XDS[50] and merged using AIMLESS[51] from the CCP4 package. ${ }^{[52]}$ Both pXd-INV-D80A complexes were indexed in the $\mathrm{P} 2{ }_{1} 2{ }_{1} 2$ space group, with two molecules in the asymmetric unit and $70 \%$ solvent content within the unit cell. The data-collection statistics are given in Supplementary Information (Table S1).

The structures of the pXd-INV-D80A complexes were solved by difference Fourier synthesis using the coordinates of the native protein (PDB code 5ANN). Crystallographic refinement was performed using the program REFMAC [53] within the CCP4 suite with flat bulk-solvent correction, maximum likelihood target features and local non-crystallographic symmetry (NCS). Free R-factor was calculated using a subset of 5\% randomly selected structure-factor amplitudes that were excluded from automated refinement. At the later stages, ligands were manually built into the electron density maps with Coot ${ }^{[54]}$ and water molecules were included in the model, which, combined with more rounds of restrained refinement, reached the R factors listed in Table S1. For hydroxytyrosol, not present in the Protein Data Bank, a PDB model was built by the online molecular editor JME[55] and the small-molecule topology generator PRODRG.[56] The model was used to automatically generate coordinates and molecular topologies suitable for REFMAC refinement.

The figures were generated with PyMOL (The PyMOL Molecular Graphics System, Version 2.0 Schrödinger, LLC). The atomic coordinates have been deposited in the Protein Data Bank under accession numbers 5NSL and 5047. 


\section{ACKNOWLEDGEMENTS}

This work was supported by grants from the Spanish Ministry of Economy and Competitiveness (BI02013-48779-C4-1/3/4 and BI02016-76601-C3-1-R/2-R/3-R), by an institutional grant from the Fundación Ramón Areces to the Centro de Biología Molecular Severo Ochoa (CBMSO), and by the European Union's Horizon 2020 research and innovation program [Blue Growth: Unlocking the potential of Seas and Oceans] under grant agreement No 634486 (INMARE). We thank the support of COST-Action CM1303 on Systems Biocatalysts. M.G-P thank the Spanish Ministry of Education for FPU Grant. We thank the staff of the Synchrotron Radiation Source at Barcelona (Alba, Spain) for providing access and for technical assistance at BL13-XALOC beamline.

Keywords: glycosylation • enzyme catalysis • enzyme specificity • olive biophenols • hydroxytyrosol

[1] S. H. Omar, P. G. Kerr, C. J. Scott, A. S. Hamlin, H. K. Obied, Molecules 2017, 22(11),1858.

[2] R. Ciriminna, F. Meneguzzo, A. Fidalgo, L. M. Ilharco, M. Pagliaro, Eur. J. Lipid Sci. Technol. 2016, 118, 503-511.

[3] H. Azaizeh, F. Halahlih, N. Najami, D. Brunner, M. Faulstich, A. Tafesh, Food Chem. 2012, 134, 2226-2234.

[4] E. Lopez-Huertas, J. Fonolla, Redox Biol. 2017, 11, 384-389.

[5] I. Medina, D. Alcantara, M. J. Gonzalez, P. Torres, R. Lucas, J. Roque, F. J. Plou, J. C. Morales, J. Agric. Food Chem. 2010, 58, 9778-9786.

[6] N. Richard, S. Arnold, U. Hoeller, C. Kilpert, K. Wertz, J. Schwager, Planta Med. 2011, 77, 18901897.

[7] J. A. González-Correa, M. D. Navas, J. A. Lopez-Villodres, M. Trujillo, J. L. Espartero, J. P. De La Cruz, Neurosci. Lett. 2008, 446, 143-146.

[8] S. Granados-Principal, J. L. Quiles, C. L. Ramirez-Tortosa, P. Sanchez-Rovira, M. C. RamirezTortosa, Nutr. Rev. 2010, 68, 191-206.

[9] M. González-Santiago, J. Fonollá, E. Lopez-Huertas, Pharmacol. Res. 2010, 61, 364-370.

[10] T. A. Wani, F. A. Masoodi, A. Gani, W. N. Baba, N. Rahmanian, R. Akhter, I. A. Wani, M. Ahmad, Trends Food Sci. Technol. 2018, 77, 77-90.

[11] M. C. Lopez de las Hazas, L. Rubio, A. Macia, M. J. Motilva, Curr. Pharm. Des. 2018, 24, DOI : 10.2174/1381612824666180522110314.

[12] EFSA Panel on Dietetic Products, Nutrition and Allergies (NDA). EFSA Journal 2011, 9, 2033-2058.

[13] O. Khymenets, M. Fitó, S. Touriño, D. Muñoz-Aguayo, M. Pujadas, J. L. Torres, J. Joglar, M. Farré, M. I. Covas, R. De La Torre, Drug Metab. Dispos. 2010, 38, 1417-1421.

[14] E. Giordano, O. Dangles, N. Rakotomanomana, S. Baracchini, F. Visioli, Food Funct. 2015, 6, 3275-3281.

[15] D. V. Ratnam, D. D. Ankola, V. Bhardwaj, D. K. Sahana, M. N. V. R. Kumar, J. Controlled Release 2006, 113, 189-207.

[16] P. Torres, A. Poveda, J. Jimenez-Barbero, J. L. Parra, F. Comelles, A. O. Ballesteros, F. J. Plou, Adv. Synth. Catal. 2011, 353, 1077-1086.

[17] A. Lepak, A. Gutmann, S. T. Kulmer, B. Nidetzky, ChemBioChem 2015, 16, 1870-1874. 
[18] J. González-Alfonso, D. Rodrigo-Frutos, E. Belmonte-Reche, P. Peñalver, A. Poveda, J. Jiménez-Barbero, A. Ballesteros, Y. Hirose, J. Polaina, J. Morales, M. Fernández-Lobato, F. Plou, Molecules 2018, 23(6), 1271.

[19] T. Desmet, W. Soetaert, Biocatal. Biotransform. 2011, 29, 1-18.

[20] Q. Li, J. Wang, Y. Li, X. Xu, Mol. Med. Rep. 2018, 17, 7287-7292.

[21] M. Zduriencikova, D. Cholujova, J. Duraj, M. Mastihubova, V. Mastihuba, E. Karnisova Potocka, E. Galova, A. Sevcovicova, M. Klapakova, E. Horvathova, Basic Clin. Pharmacol. Toxicol. 2018, 122, 346-354.

[22] A. Trincone, E. Pagnotta, A. Tramice, Bioresour. Technol. 2012, 115, 79-83.

[23] M. Nieto-Domínguez, L. I. de Eugenio, P. Peñalver, E. Belmonte-Reche, J. C. Morales, A. Poveda, J. Jiménez-Barbero, A. Prieto, F. J. Plou, M. J. Martínez, J. Agric. Food Chem. 2017, 65, 10526-10533

[24] E. Karnišová Potocká, M. Mastihubová, V. Mastihuba, Biocatal. Biotransform. 2018, DOI:10.1080/10242422.2017.1423060.

[25] R. Lucas, D. Alcantara, J. C. Morales, Carbohydr. Res. 2009, 344, 1340-1346.

[26] O. Khymenets, M. Farré, M. Pujadas, E. Ortiz, J. Joglar, M. I. Covas, R. De La Torre, Food Chem. 2011, 126, 306-314.

[27] F. Zhou, W. Huang, M. Li, Y. Zhong, M. Wang, B. Lu, J. Agric. Food Chem. 2018, 66, 46304637.

[28] B. Rodriguez-Colinas, A. Poveda, J. Jimenez-Barbero, A. O. Ballesteros, F. J. Plou, J. Agric Food Chem. 2012, 60, 6391-6398.

[29] L. Fernandez-Arrojo, D. Marin, A. G. de Segura, D. Linde, M. Alcalde, P. Gutierrez-Alonso, I. Ghazi, F. J. Plou, M. Fernandez-Lobato, A. Ballesteros, Process Biochem. 2007, 42, 1530-1536.

[30] M. Ferrer, A. Beloqui, O. V. Golyshina, F. J. Plou, A. Neef, T. N. Chernikova, L. FernándezArrojo, I. Ghazi, A. Ballesteros, K. Elborough, K. N. Timmis, P. N. Golyshin, Biotechnol. J., 2007, 2, 207-213.

[31] F. J. Plou, A. Gómez de Segura, A. Ballesteros, in Industrial enzymes: Structure, Function and Application (Eds.: J. Polaina, A. P. MacCabe), Springer, New York, 2007, pp. 141-157.

[32] T. Desmet, W. Soetaert, P. Bojarová, V. Kren, L. Dijkhuizen, V. Eastwick-Field, A. Schiller, Chem. - Eur. J. 2012, 18, 10786-10801.

[33] L. Lu, L. Xu, Y. Guo, D. Zhang, T. Qi, L. Jin, G. Gu, L. Xu, M. Xiao, PLoS One 2015, 10.

[34] M. Minig, L. S. Mazzaferro, R. Erra-Balsells, G. Petroselli, J. D. Breccia, J. Agric. Food Chem. 2011, 59, 11238-11243.

[35] A. Herrera-González, G. Núñez-López, S. Morel, L. Amaya-Delgado, G. Sandoval, A. Gschaedler, M. Remaud-Simeon, J. Arrizon, Appl. Microbiol. Biotechnol. 2017, 101, 5223-5234.

[36] D. Linde, I. Macias, L. Fernandez-Arrojo, F. J. Plou, M. Fernandez-Lobato, Appl. Environ. Microbiol. 2009, 75, 1065-1073.

[37] D. Linde, B. Rodríguez-Colinas, M. Estévez, A. Poveda, F. J. Plou, M. Fernández Lobato, Bioresour. Technol. 2012, 109, 123-130.

[38] N. Míguez, M. Gimeno-Pérez, D. Fernández-Polo, F. Cervantes, A. Ballesteros, M. Fernández-Lobato, M. Ribeiro, F. Plou, Catalysts 2018, 8, 201.

[39] M. Gimeno-Perez, P. Santos-Moriano, L. Fernandez-Arrojo, A. Poveda, J. Jimenez-Barbero, A. 0. Ballesteros, M. Fernandez-Lobato, F. J. Plou, Process Biochem. 2014, 49, 423-429.

[40] M. Ramirez-Escudero, M. Gimeno-Perez, B. Gonzalez, D. Linde, Z. Merzdo, M. FernandezLobato, J. Sanz-Aparicio, J. Biol. Chem. 2016, 291, 6843-6857. 
[41] M. Gimeno-Perez, D. Linde, L. Fernandez-Arrojo, F. J. Plou, M. Fernandez-Lobato, Appl. Microbiol. Biotechnol. 2015, 99, 3459-3467.

[42] M. E. Dirks-Hofmeister, T. Verhaeghe, K. De Winter, T. Desmet, Angew. Chem., Int. Ed. 2015, 54, 9289-9292.

[43] E. Potocká, M. Mastihubová, V. Mastihuba, J. Mol. Catal. B: Enzym. 2015, 113, 23-28.

[44] D. Piedrabuena, N. Míguez, A. Poveda, F. J. Plou, M. Fernández-Lobato, Appl. Microbiol. Biotechnol. 2016, 100, 8769-8778.

[45] J. L. Asensio, A. Ardá, F. J. Cañada, J. Jiménez-Barbero, Acc. Chem. Res. 2013, 46, 946-954.

[46] A. Ardá, J. Jiménez-Barbero, Chem. Commun. 2018, 54, 4761-4769.

[47] M. Kraus, C. Grimm, J. Seibel, Chem. Commun. 2017, 53, 12181-12184.

[48] I. Ghazi, L. Fernandez-Arrojo, H. Garcia-Arellano, M. Ferrer, A. Ballesteros, F. J. Plou, J. Biotechnol. 2007, 128, 204-211.

[49] A. Polo, D. Linde, M. Estevez, M. Fernandez-Lobato, J. Sanz-Aparicio, Acta Crystallogr., Sect. F: Struct. Biol. Cryst. Commun. 2010, 66, 1441-1444.

[50] W. Kabsch, Acta Crystallogr., Sect. D: Biol. Crystallogr. 2010, 66, 125-132.

[51] P. R. Evans, G. N. Murshudov, Acta Crystallogr., Sect. D: Biol. Crystallogr. 2013, 69, 12041214.

[52] M. D. Winn, C. C. Ballard, K. D. Cowtan, E. J. Dodson, P. Emsley, P. R. Evans, R. M. Keegan, E. B. Krissinel, A. G. W. Leslie, A. McCoy, S. J. McNicholas, G. N. Murshudov, N. S. Pannu, E. A. Potterton, H. R. Powell, R. J. Read, A. Vagin, K. S. Wilson, Acta Crystallogr., Sect. D: Biol. Crystallogr. 2011, 67, 235-242.

[53] G. N. Murshudov, A. A. Vagin, E. J. Dodson, Acta Crystallogr., Sect. D: Biol. Crystallogr. 1997, $53,240-255$.

[54] P. Emsley, K. Cowtan, Acta Crystallogr., Sect. D: Biol. Crystallogr. 2004, 60, 2126-2132.

[55] P. Ertl, J. Cheminf. 2010, 2.

[56] A. W. Schüttelkopf, D. M. F. Van Aalten, Acta Crystallogr., Sect. D: Biol. Crystallogr. 2004, 60, 1355-1363. 


\section{Entry for the Table of Contents}

\section{FULL PAPER}

Hydroxytyrosol was fructosylated by the $\beta$ fructofuranosidase from the yeast Xanthophyllomyces dendrorhous, and the reaction mechanism was elucidated by crystallography analyzing the complexes

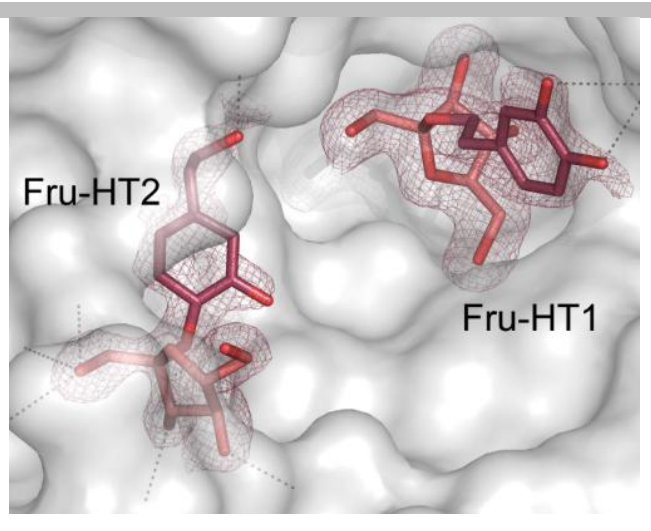
with the substrates and
N. Míguez, M. RamírezEscudero, M. Gimeno-Pérez, A. Poveda, J. JiménezBarbero, A. O. Ballesteros, M. Fernández-Lobato, J. Sanz-Aparicio* and F. J. Plou* $^{*}$

Page No. - Page No.

Fructosylation of berdmonerevermanol berthon 


\section{Supplementary material}

\section{Production of fructosyl-hydroxytyrosol by the $\beta$ - fructofuranosidase from Xanthophyllomyces dendrorhous: Insights into the molecular basis of the enzyme specificity.}

N. Míguez, a M. Ramírez-Escudero, ${ }^{\mathrm{b}}$ M. Gimeno-Pérez,c, A. Poveda, d J. JiménezBarbero, ${ }^{\text {d }}$ A. O. Ballesteros, ${ }^{a}$ M. Fernández-Lobato, ${ }^{c}$ J. Sanz-Aparicio,b, and F. J. Plou, ${ }^{\text {, }}$

a Institute of Catalysis and Petrochemistry, CSIC, 28049 Madrid, Spain.

${ }^{b}$ Macromolecular Crystallography and Structural Biology Dept., Institute of PhysicalChemistry Rocasolano, CSIC, Serrano 119, 28006 Madrid, Spain.

${ }^{c}$ Centre of Molecular Biology Severo Ochoa (CSIC-UAM), Molecular Biology Department. Autonomous University of Madrid, 28049 Madrid, Spain.

${ }^{d}$ cCIC bioGUNE,; Biscay Science and Technology Park, 801-A Ibaizabal Bidea St., Derio town 48160, Spain. 


\begin{tabular}{|c|c|}
\hline Table S1. & $\begin{array}{l}\text { Crystallographic statistics for the complexes between Xd-INVD80A and: (i) Fructose } \\
\text { + Hydroxytyrosol; (ii) Fructosyl-Hydroxytyrosol }\end{array}$ \\
\hline Figure S1. & MS spectrum of Fru-HT1 \\
\hline \multicolumn{2}{|r|}{ NMR Spectra ( $\left.800 \mathrm{MHz}, \mathrm{D}_{2} \mathrm{O}, 298 \mathrm{~K}\right)$ for compound Fru-HT1 } \\
\hline Figure S2. & DEPT-HSQC, general view \\
\hline Figure S3. & $\begin{array}{l}\text { DEPT-HSQC, sugar (right) and aromatic region (left), showing the signal } \\
\text { assignations }\end{array}$ \\
\hline Figure S4. & HSQC-TOCSY, general view \\
\hline Figure S5. & HMBC, general view \\
\hline Figure S6. & NOESY (right) and COSY (left) spectra \\
\hline Figure S7. & ${ }^{13} \mathrm{C}$ NMR spectrum \\
\hline Figure S8. & $\begin{array}{l}\text { Identification of the aromatic part of the two compounds in the mixture. (a) } \\
\text { Aromatic part of HT, from a different sample of pure HT . From the study sample: } \\
\text { (b) Aromatic part of Fru-HT1; (c) Selective 1D TOCSY spectrum of the spin } \\
\text { system of HT; (d) Selective 1D TOCSY spectrum of the spin system of Fru-HT1; } \\
\text { (e) Selective 1D-NOESY spectrum from the proton FruH6a, indicating stacking } \\
\text { between the sugar ring and the aromatic surface; (f) 1H spectrum with diffusion } \\
\text { filter in which the HT signals starts to decrease, showing that both compounds } \\
\text { have different molecular weight. }\end{array}$ \\
\hline Figure S9. & Lower energy conformer generated with Macromodel software. \\
\hline
\end{tabular}


Table S1. Crystallographic statistics. Values in parentheses are for the high resolution shell.

\begin{tabular}{|c|c|c|}
\hline Crystal data & $\begin{array}{l}\text { Xd-INVD80A / Fructose + } \\
\text { Hydroxytyrosol }\end{array}$ & $\begin{array}{c}\text { Xd-INVD80A / } \\
\text { Fructosyl- } \\
\text { Hydroxytyrosol }\end{array}$ \\
\hline Space group & $P 2{ }_{1} 2{ }_{1} 2$ & $P 2{ }_{1} 2_{1} 2$ \\
\hline \multicolumn{3}{|l|}{ Unit cell parameters } \\
\hline $\mathrm{a}(\AA)$ & 74.86 & 74.62 \\
\hline $\mathrm{b}(\AA)$ & 206.12 & 205.36 \\
\hline c $(\AA)$ & 145.53 & 146.94 \\
\hline \multicolumn{3}{|l|}{ Data collection } \\
\hline Beamline & XALOC (ALBA) & XALOC (ALBA) \\
\hline Temperature $(\mathrm{K})$ & 100 & 100 \\
\hline Wavelength $(\AA)$ & 0.97949 & 0.97926 \\
\hline Resolution $(\AA)$ & $\begin{array}{l}84.11-1.70 \\
(1.70-1.73) \\
\end{array}$ & $\begin{array}{l}48.98-1.91 \\
(1.91-1.94) \\
\end{array}$ \\
\hline \multicolumn{3}{|l|}{ Data processing } \\
\hline Total reflections & $1669813(82808)$ & $1183319(58499)$ \\
\hline Unique reflections & 247009 (12089) & $175297(8563)$ \\
\hline Multiplicity & $6.8(6.8)$ & $6.8(6.8)$ \\
\hline Completeness (\%) & $100.0(100.0)$ & $100.0(100.0)$ \\
\hline Mean $I / \sigma(I)$ & $18.7(3.0)$ & $19.0(3.8)$ \\
\hline$R_{\text {merge }}{ }^{+}(\%)$ & $5.8(58.6)$ & $7.2(58.8)$ \\
\hline$R_{\text {pim }}{ }^{\dagger \dagger}(\%)$ & $2.4(24.2)$ & $3.0(24.3)$ \\
\hline Molecules per ASU & 2 & 2 \\
\hline Refinement & $17.7 / 18.9$ & $16.8 / 18.2$ \\
\hline \multicolumn{3}{|l|}{$\mathrm{R}_{\text {work }} / \mathrm{R}_{\text {free }}$} \\
\hline $\mathbf{N}^{0}$ of atoms/average $\mathbf{B}\left(\AA^{2}\right)$ & $12354 / 25.54$ & $12027 / 27.18$ \\
\hline Protein & $9612 / 21.66$ & $9627 / 24.00$ \\
\hline Carbohydrate & $828 / 39.97$ & $845 / 45.29$ \\
\hline Other compounds & $609 / 47.11$ & $174 / 39.30$ \\
\hline Water molecules & $1305 / 35.43$ & $1381 / 36.16$ \\
\hline \multicolumn{3}{|l|}{ Ramachandran plot (\%) } \\
\hline Favoured & 96.0 & 95.0 \\
\hline Outliers & 0 & 0 \\
\hline \multicolumn{3}{|l|}{ RMS deviations } \\
\hline Bonds $(\AA)$ & 0.006 & 0.006 \\
\hline Angles $\left({ }^{\circ}\right)$ & 1.344 & 1.413 \\
\hline PDB accession codes & 5NSL & 5047 \\
\hline
\end{tabular}

${ }^{\dagger} \mathrm{R}_{\text {merge }}=\sum_{\mathrm{hkl}} \sum_{\mathrm{i}}\left|\mathrm{I}_{\mathrm{i}}(\mathrm{hkl})-[\mathrm{I}(\mathrm{hkl})]\right| / \sum_{\mathrm{hkl}} \sum_{\mathrm{i}} \mathrm{I}_{\mathrm{i}}(\mathrm{hkl})$, where $\mathrm{I}_{\mathrm{i}}(\mathrm{hkl})$ is the ith measurement of reflection hkl and $[\mathrm{I}(\mathrm{hkl})]$ is the weighted mean of all measurements.

${ }^{\dagger} \mathrm{R}_{\mathrm{pim}}=\sum_{\mathrm{hkl}}[1 /(\mathrm{N}-1)] 1 / 2 \sum_{\mathrm{i}}\left|\mathrm{I}_{\mathrm{i}}(\mathrm{hkl})-[\mathrm{I}(\mathrm{hkl})]\right| / \sum_{\mathrm{hkl}} \sum_{\mathrm{i}} \mathrm{I}_{\mathrm{i}}(\mathrm{hkl})$, where $\mathrm{N}$ is the redundancy for the hkl reflection.

${ }^{\dagger \dagger} R_{\text {work }} / R_{\text {free }}=\sum_{\text {hkl }}|\mathrm{Fo}-\mathrm{Fc}| / \sum_{\text {hkl }}\left|F_{0}\right|$, where $\mathrm{Fc}_{\mathrm{c}}$ is the calculated and Fo is the observed structure factor amplitude of reflection hkl for the working / free (5\%) set, respectively. 
Fig. S1. MS spectrum of fructosyl-HT

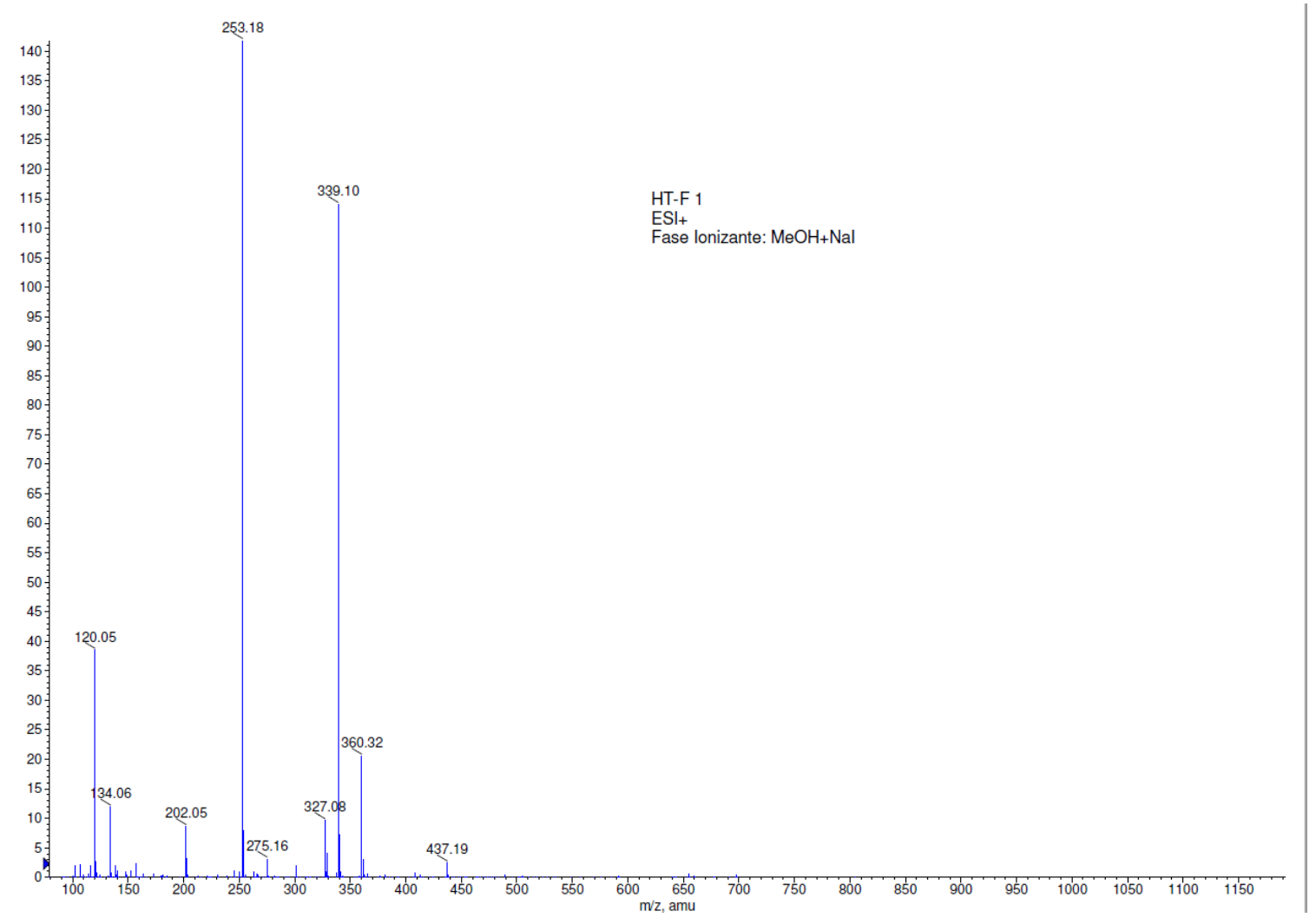


Fig. S2. NMR Spectra (800 MHz, $\left.\mathrm{D}_{2} \mathrm{O}, 298 \mathrm{~K}\right)$ for compound Fru-HT1: DEPT-HSQC, general view.

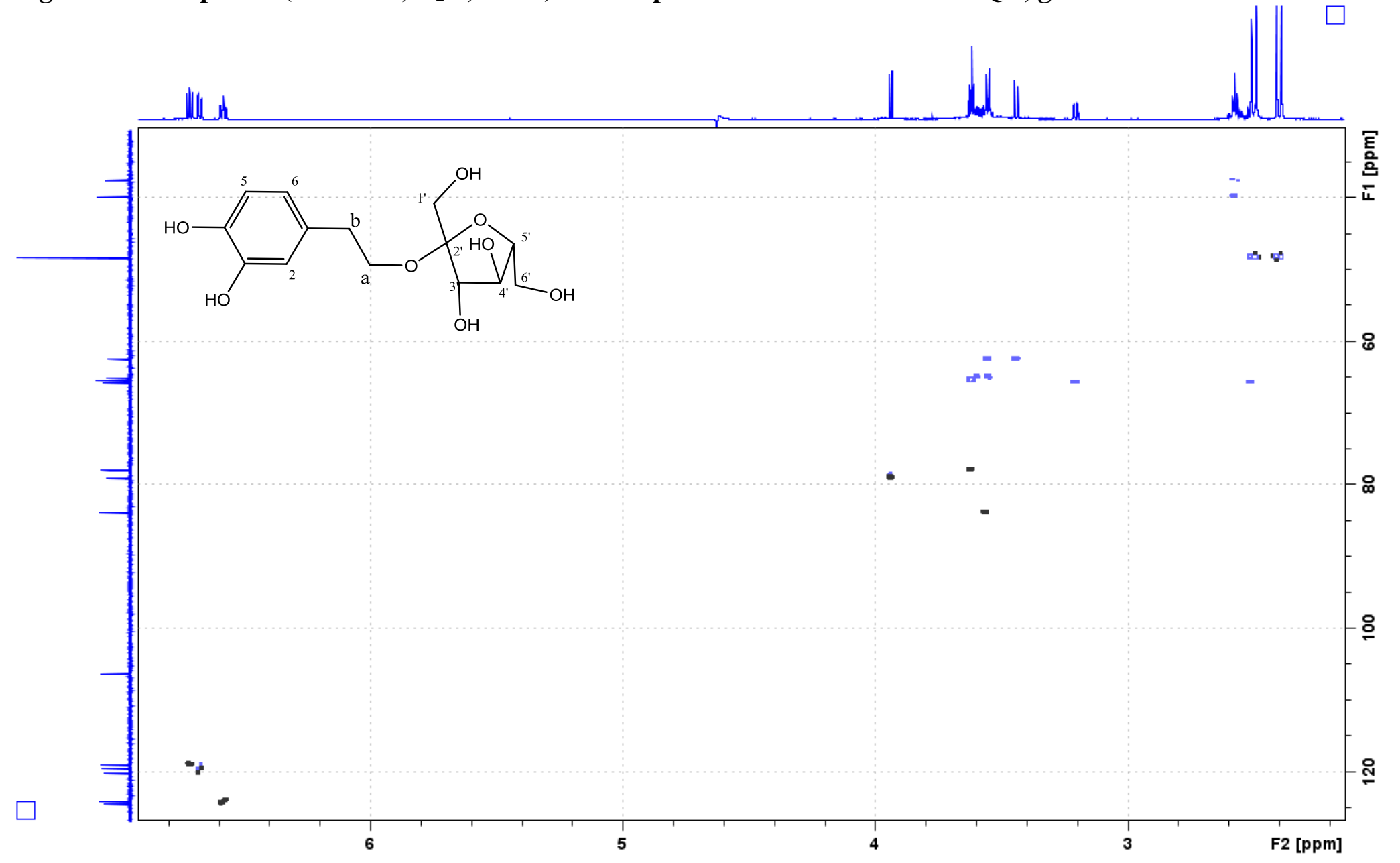


Fig. S3. NMR Spectra (800 MHz, $\mathrm{D}_{2} \mathrm{O}, 298 \mathrm{~K}$ ) for compound Fru-HT1: DEPT-HSQC, sugar (right) and aromatic region (left), showing the signal assignations

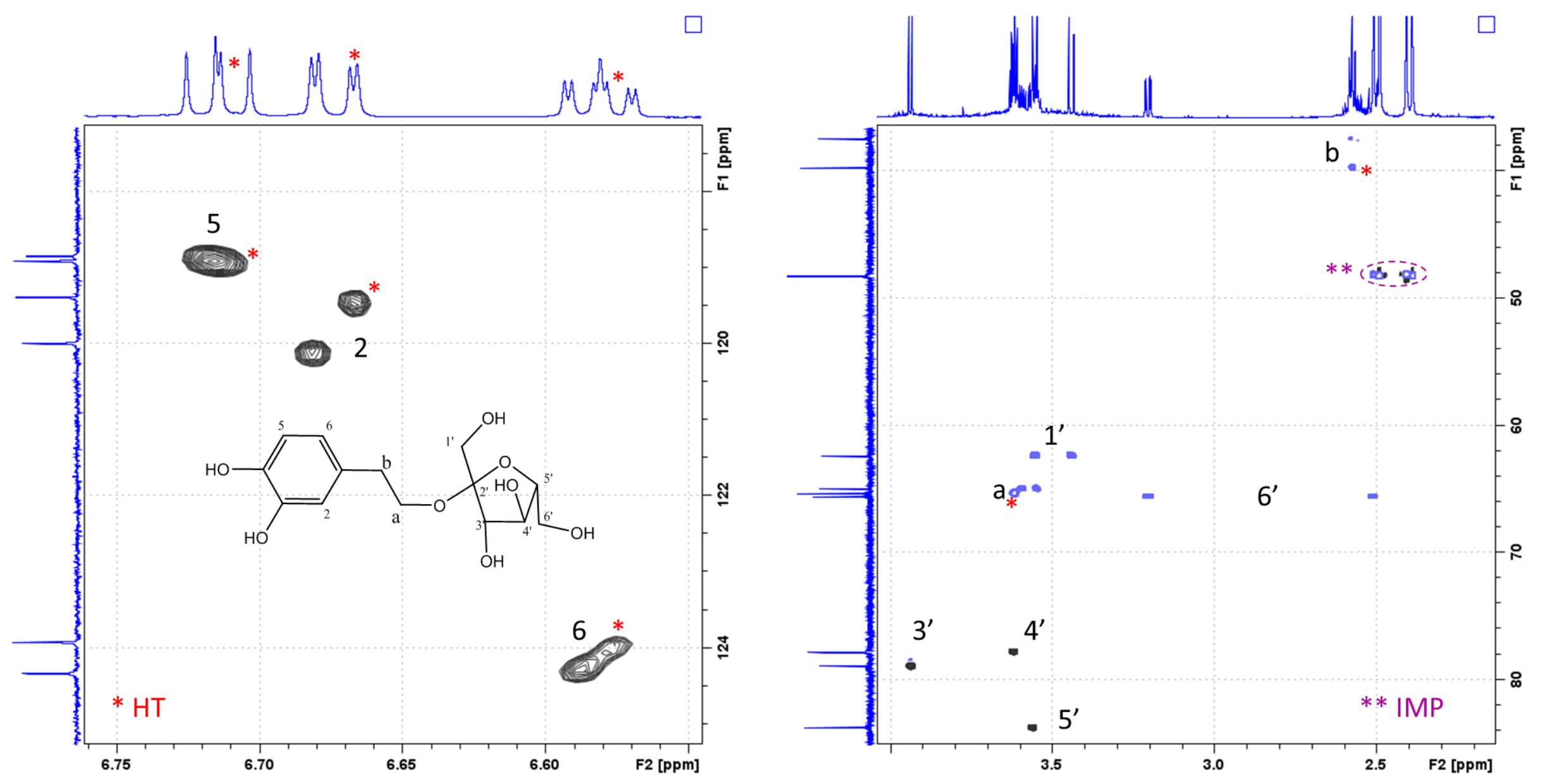


Fig. S4. NMR Spectra (800 MHz, $\left.\mathrm{D}_{2} \mathrm{O}, 298 \mathrm{~K}\right)$ for compound Fru-HT1: HSQC-TOCSY, general view.

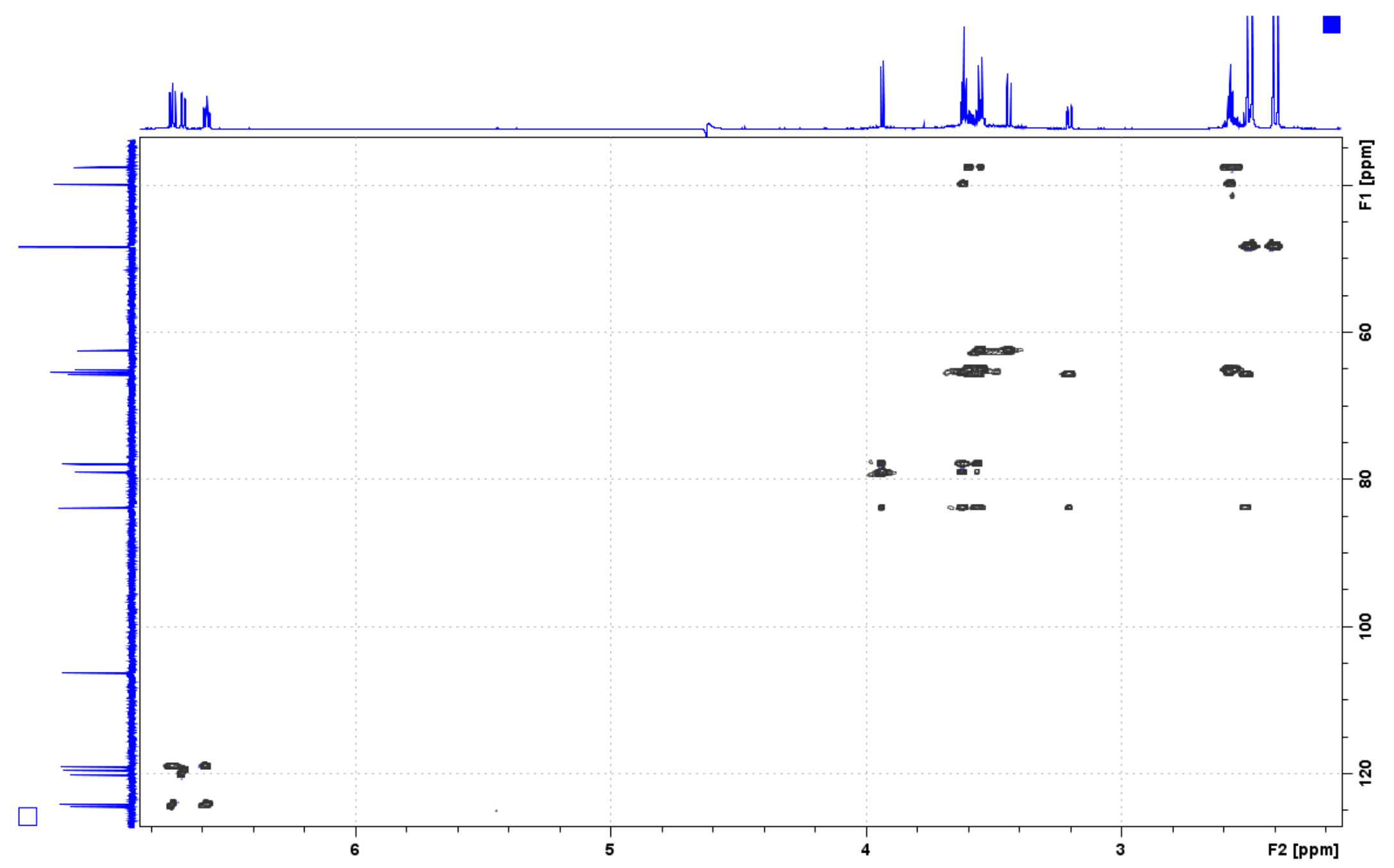


Fig. S5. NMR Spectra (800 MHz, $D_{2} 0,298 K$ ) for compound Fru-HT1: HMBC, general view.

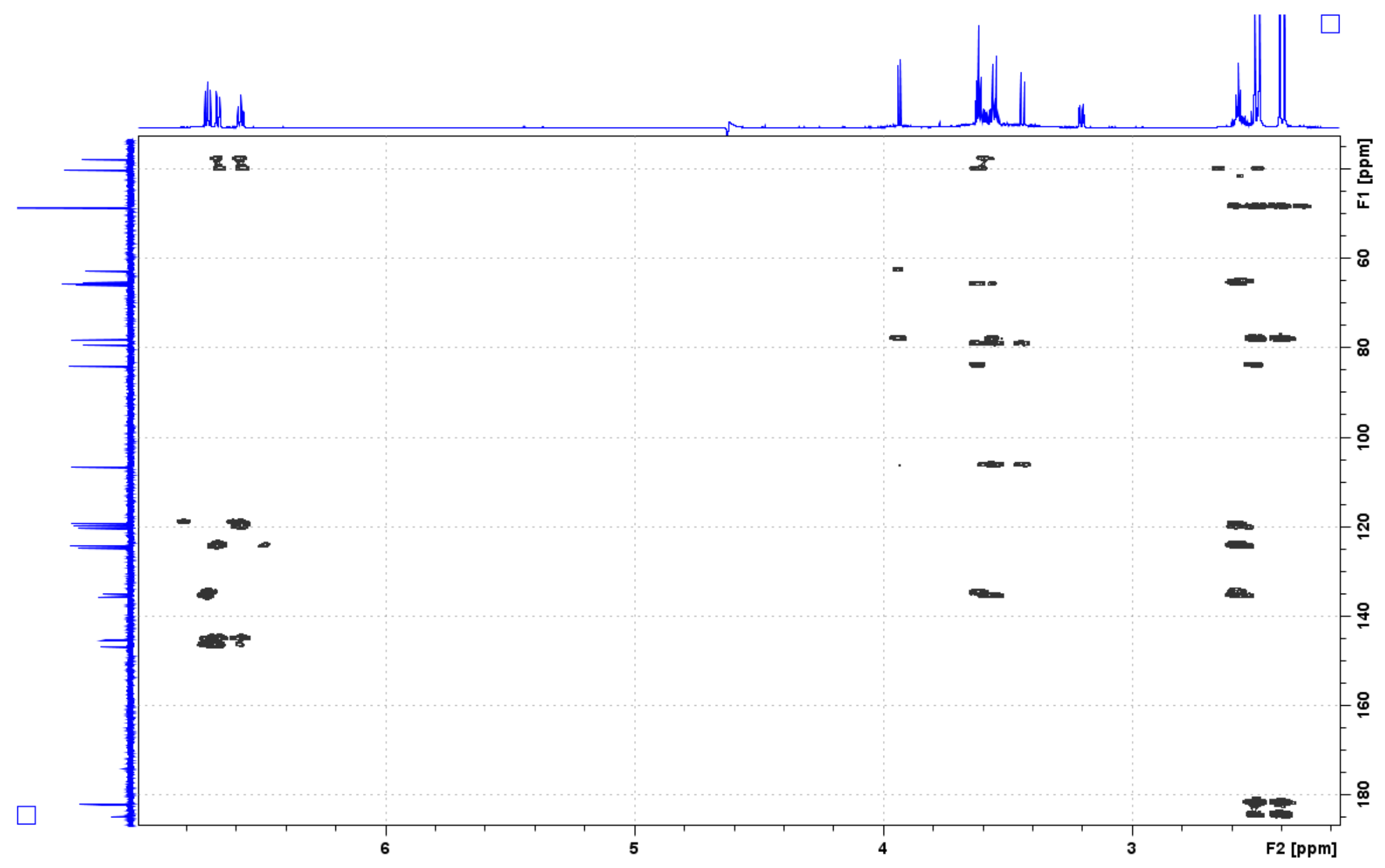


Fig. S6. NMR Spectra (800 MHz, $\left.D_{2} 0,298 K\right)$ for compound Fru-HT1: NOESY (right) and COSY (left) spectra.

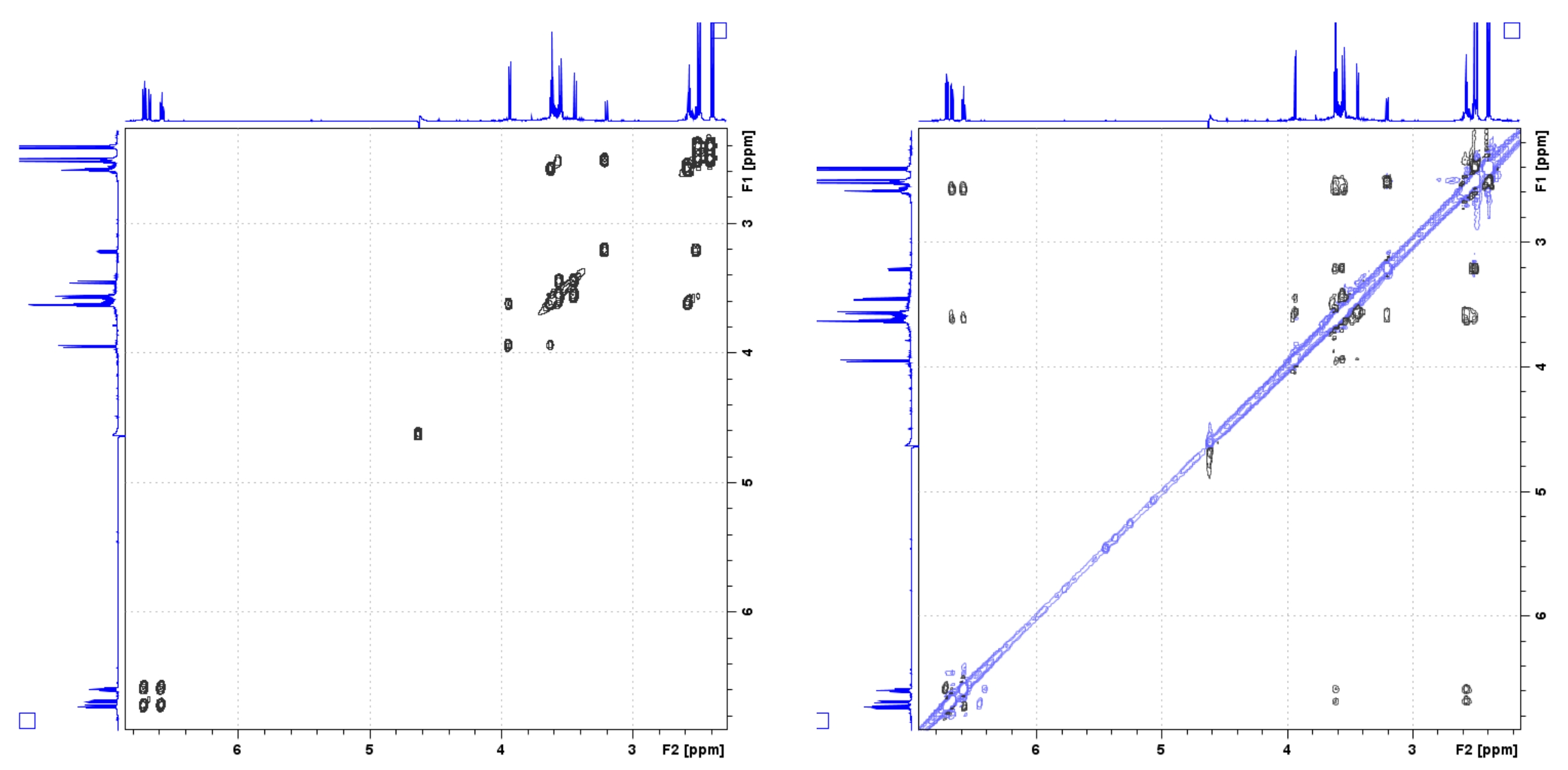


Fig. S7. NMR Spectra (800 MHz, $\left.\mathrm{D}_{2} \mathrm{O}, 298 \mathrm{~K}\right)$ for compound Fru-HT1: ${ }^{13} \mathrm{C}$ NMR spectrum.

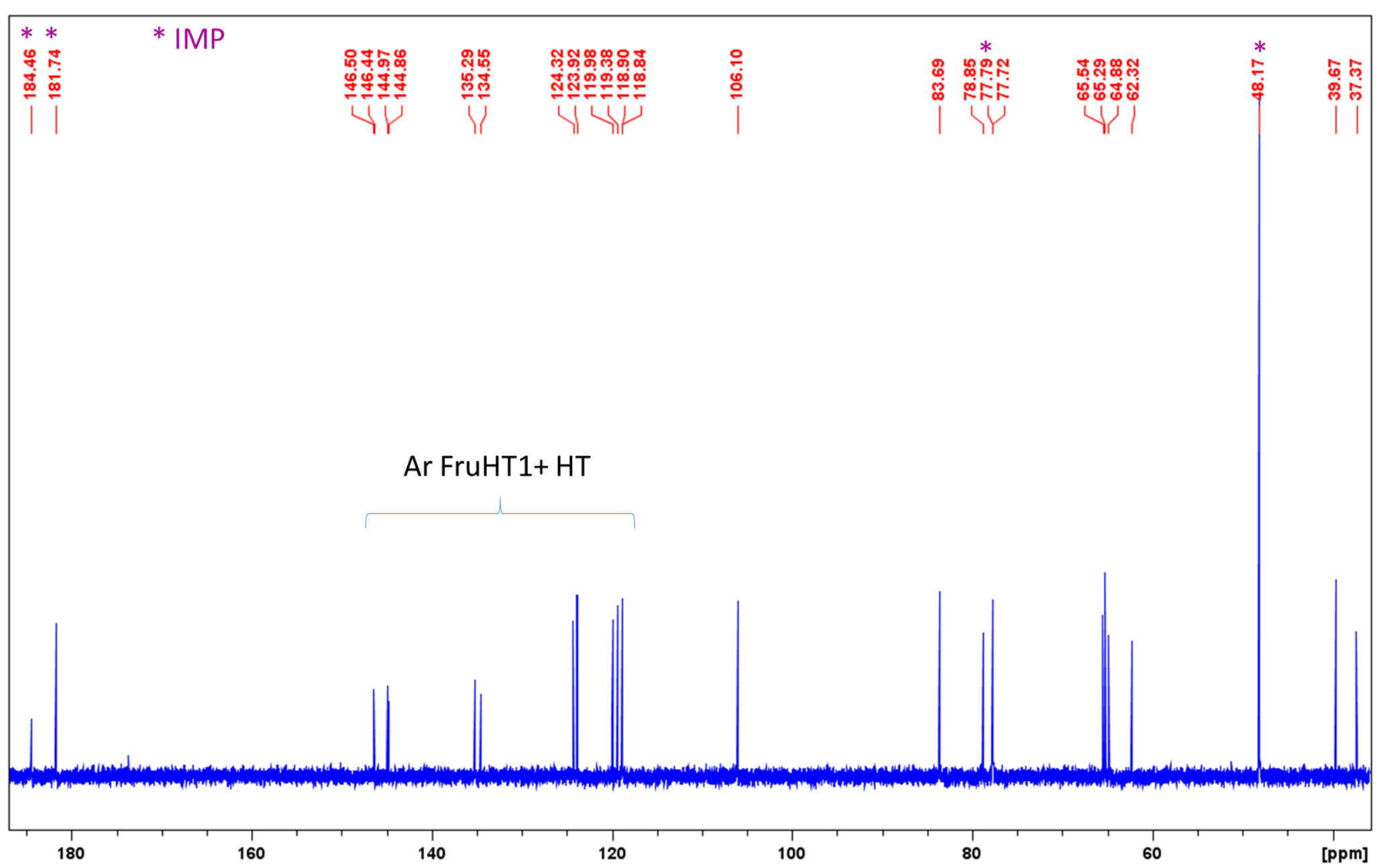


Fig. S8. Identification of the aromatic part of the two compounds in the mixture. (a) Aromatic part of HT, from a different sample of pure HT . From the study sample: (b) Aromatic part of Fru-HT1; (c) Selective 1D TOCSY spectrum of the spin system of HT; (d) Selective 1D TOCSY spectrum of the spin system of Fru-HT1; (e) Selective 1D-NOESY spectrum from the proton FruH6a, indicating stacking between the sugar ring and the aromatic surface; (f) ${ }^{1} \mathrm{H}$ spectrum with diffusion filter in which the $\mathrm{HT}$ signals starts to decrease, showing that both compounds have different molecular weight.

a)

$$
\text { Sample: HT }
$$

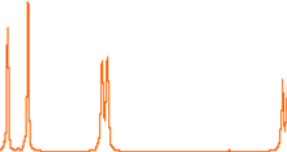

Study sample: Fru-HT1 + HT

b)

c)

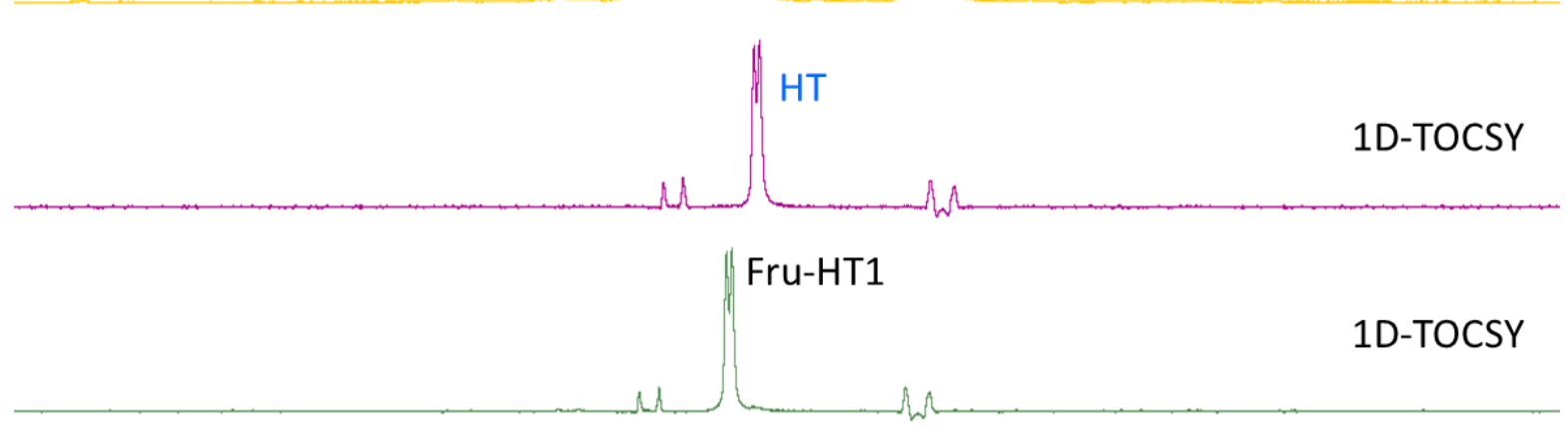

e)

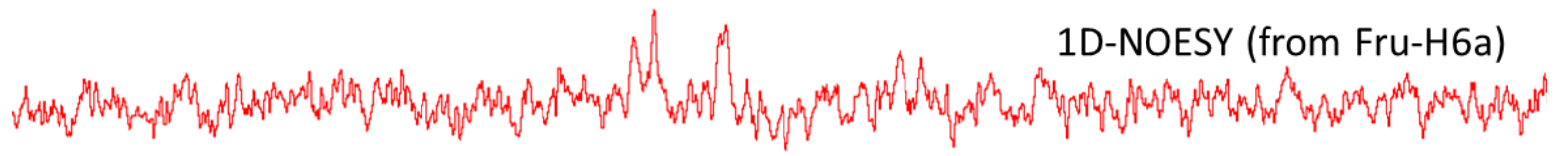

f)

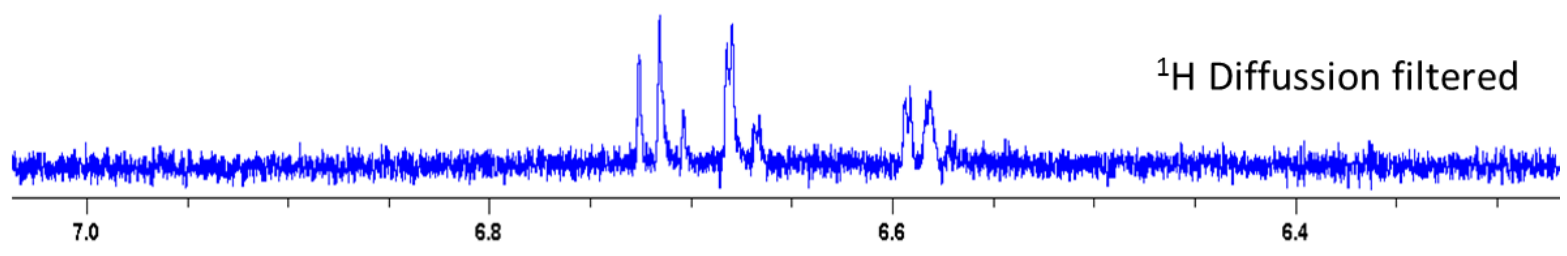


Fig. S9. Lower energy conformer generated with Macromodel software. The proposed structure is in agreement with the NMR data.

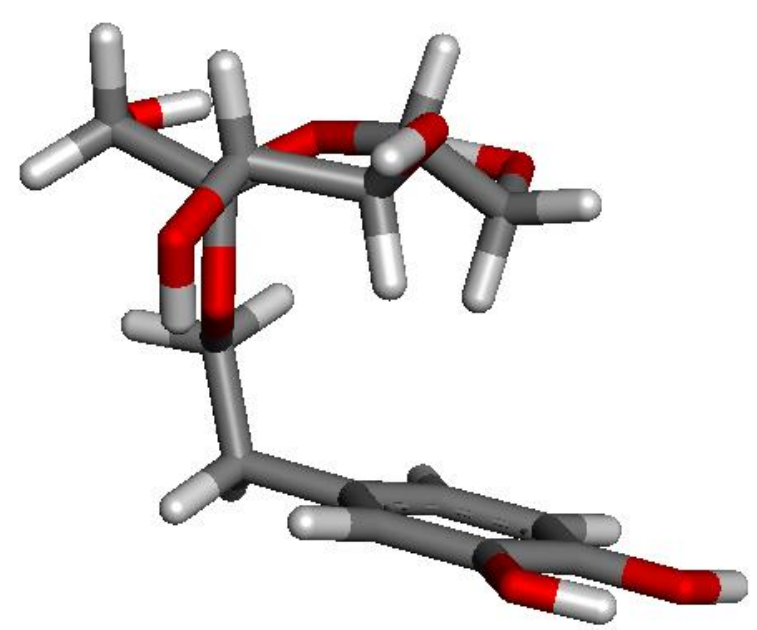

